\title{
Factors influencing the acceptability of object fronting in German
}

\author{
Marta Wierzba $^{1} \cdot$ Gisbert Fanselow $^{1}$
}

Received: 12 October 2016/Accepted: 5 May 2019/Published online: 8 April 2020

(C) The Author(s) 2020

\begin{abstract}
In this paper, we address some controversially debated empirical questions concerning object fronting in German by a series of acceptability rating studies. We investigated three kinds of factors: (i) properties of the subject (given/ new, pronoun/full DP), (ii) emphasis, (iii) register. The first factor is predicted to play a crucial role by models in which object fronting possibilities are limited by prosodic properties. Two experiments provide converging evidence for a systematic effect of this factor: we find that the relative acceptability of object fronting across subjects that require an accent (new DPs) is lower than across deaccentable subjects (pronouns and given DPs). Other models predict object fronting across full phrases (but not across pronouns) to be limited to an emphatic interpretation. This prediction is also borne out, suggesting that both types of models capture an empirically valid generalization and can be seen as complementing each other rather than competing with each other. Finally, we find support for the view that informal register facilitates object fronting. In sum, our experiments contribute to clarifying the empirical basis concerning a phenomenon influenced by a range of interacting factors. This, in turn, informs theoretical approaches to the prefield position and helps to identify factors that need to be carefully controlled in this field of research.
\end{abstract}

Keywords German · Object fronting · Prefield · Givenness · Emphasis · Register · Experiments · Acceptability

Marta Wierzba

wierzba@uni-potsdam.de

Gisbert Fanselow

fanselow@uni-potsdam.de

1 Department Linguistik, Universität Potsdam, Haus 14, Karl-Liebknecht-Straße 24-25, 14476

Potsdam, Germany 


\section{Introduction}

German is a verb-second (V2) language: any of a main clause's constituents can occupy the leftmost position, i.e., the prefield preceding the finite verb. ${ }^{1}$ However, in general, object-initial sentences as in (1b) are more restricted in their use than subject-initial ones as in (1a). A subject-initial sentence such as (1a) is fully acceptable in a wide variety of contexts (if not in all); for example, (1a) could be a felicitous answer to a wide-focus question like "What happened?" In contrast, an object-initial sentence such as (1b) can only be used in a limited set of contexts, i.e., it is more marked in the sense of Höhle (1982). One typical function of object fronting is the expression of a narrow focus, e.g., in contrastive contexts.

(1) a. Eine Frau hat ein Buch gelesen. a woman has a book read

'A woman has read a book.'

b. Ein Buch hat eine Frau gelesen.

However, as was first observed by Höhle (1982), Jacobs (1991), Büring (1997), and Krifka (1998), object fronting is sometimes well-formed even in wide-focus contexts. Both sentences in (2) can answer questions such as "What happened?" or "What did she do?"

(2) a. Sie/ die Frau hat ein Buch gelesen.

shel the woman has a book read

'She/the woman has read a book.'

b. Ein Buch hat sie/die Frau gelesen.

Based on examples like these, the conditions under which wide-focus object fronting is possible have been debated. One conspicuous feature of the examples reported to be felicitous in the literature is that the subject is often a pronoun (Büring 1997; Krifka 1998) or a definite, discourse-given DP (Höhle 1982)-is this a necessary condition for object fronting? Another controversial question is whether the fronted object obtains an emphatic interpretation in sentences like (2b). The answers to these questions have consequences for the theoretical analysis of movement to the prefield position: to decide whether it should be analyzed as feature-driven operator movement or not, it is relevant to know what kinds of elements act as interveners and whether the movement comes with specific interpretative effects.

The present paper attempts to address these empirical questions by interpreting the results of seven acceptability rating experiments.

Experiments 1-2 (reported in Sect. 3) study the influence of the subject type: does it matter for the acceptability of object fronting whether the subject is discourse-given or discourse-new, and whether it is pronominal or non-pronominal? These experiments are designed to test the predictions of accounts according to

\footnotetext{
${ }^{1}$ For a general overview of prefield properties, see, e.g., Fanselow (2002) and Speyer (2008).
} 
which the availability of object fronting depends on whether the intervening material can be easily deaccented, such as pronouns or given expressions (as argued, e.g., by Fanselow and Lenertová 2011). Our results show that object fronting is indeed facilitated when the crossed subject is a definite pronoun or a given phrase, as opposed to a new phrase.

Experiments 3-5 (reported in Sect. 4) examine the factor emphasis: is object fronting facilitated when cues for emphasis are present? In Experiment 3, we see a general facilitating effect on object fronting. In Experiment 4, in which the factor emphasis is crossed with the factor subject type, we see an interaction between the two factors. The observed pattern is compatible with an idea proposed by Frey (2010), namely that only pronouns can be crossed in the absence of an emphatic interpretation. In Experiment 5, we investigate the latter idea further by comparing emphasis-related movement to different kinds of operator movement. The results are compatible with the assumption that these are similar operations.

In Experiments 6-7 (reported in Sect. 5), we take a closer look at register: is object fronting more acceptable in informal speech? Considering register as a potential factor is motivated by the concern that emphasis was correlated with informal register in Experiment 3. The results of Experiment 6 suggest that cues of an informal register facilitate object fronting. This explains some partly contradictory findings in Experiments 3 and 4, and it shows that register is an important factor to consider whenever object fronting is tested. In Experiment 7, we test whether the facilitating effect also arises when the cues of informal register are included in the filler materials rather than in the test items themselves. We find a trend in the same direction, but no significant effect.

It is crucial to note that throughout the paper, we limit the discussion to relative acceptability of object fronting, i.e., we interpret only the relative acceptability difference between subject-initial order and object-initial order. The reason for this is that the properties that we manipulate in the experiments can affect acceptability independently of what is fronted, and we want to factor out this part of the effect. To give an example: in Experiment 1, we compare different types of subjects. In addition to pronouns as in (3a, b), we also look at full DPs as in (3c, d).

(3) a. Sie hat ein Buch gelesen. she has a book read

'She has read a book.'

b. Ein Buch hat sie gelesen.

c. Die Frau hat ein Buch gelesen. the woman has a book read

'The woman has read a book.'

d. Ein Buch hat die Frau gelesen.

In a context like "What did the woman read?", the choice to repeat the full DP as in $(3 \mathrm{c}, \mathrm{d})$ rather than using a pronoun as in $(3 \mathrm{a}, \mathrm{b})$ could potentially change the perceived acceptability irrespective of the chosen word order. Therefore, what we will compare is not the absolute acceptability of the object-initial sentences ( $3 \mathrm{~b}$ ) versus (3d). Rather, we compare relative acceptabilities, i.e., the acceptability of the 
object-initial sentences in relation to the corresponding subject-initial ones. We do this by testing whether the acceptability difference between (3a) and (3b) is larger or smaller than the acceptability difference between (3c) and (3d) (in terms of statistical analysis, we consider the interaction between word order and the potentially facilitating factors). ${ }^{2}$ If a factor makes the difference between the subject-initial and the object-initial version significantly smaller, we speak of a facilitating effect. All occurrences of the term facilitating in this section and in the remainder of the paper are meant in this relative sense.

Before we move on to the presentation of the experiments in Sects. 3-5, Sect. 2 will provide some theoretical background on the German prefield as well as the motivation for the key features of our study design: why we decided to test object fronting in wide-focus contexts, and why we chose to investigate the factors deaccentability and emphasis.

\section{Theoretical background}

\subsection{Demarcating the empirical scope}

Following Drach (1939), den Besten (1983), and Thiersch (1978), among many others, we will assume that the prefield is (normally) filled by moving some constituent of the clause to its left edge. For ease of exposition, we will work with a 'classical' structure such as (4), in which the prefield is identified with the specifier of CP.

(4) $\left[\mathrm{CP}\right.$ ein Buch $_{\mathrm{i}}\left[\mathrm{C}\right.$ hat $\left._{\mathrm{j}}\right]$ [TP die Frau $\mathrm{t}_{\mathrm{i}}$ gelesen $\left.\mathrm{t}_{\mathrm{j}}\right]$ ]. a book has the woman read

'The woman has read a book.'

It has been observed that the left edge of the TP stands in a particularly close relation to the specifier position of CP in German (cf. Bierwisch 1963; Fanselow 2003, 2004; Müller 2004): any element that can appear in the former position in a pragmatically unmarked sentence (viz. subjects, dative objects of unaccusative and passive clauses, temporal and sentential adverbials) can also appear in the prefield without any pragmatic restrictions.

$\begin{array}{ll}\text { a. Ich } & \text { denke, dass [TP bestimmt ein Kind eine Wurst } \\ \text { I } & \text { think that } \\ \text { gegessen } & \text { hat }] .\end{array}$

'I think that definitively, a child ate a sausage.'

\footnotetext{
${ }^{2}$ Cf. Sprouse et al.'s (2012) factorial design for testing island effects: to isolate the specific acceptability penalty of island violations (on top of potential penalties for the complexity of movement and the presence of a syntactic island), they consider the interaction between movement and type of structure from which the extraction took place (island/non-island).
} 


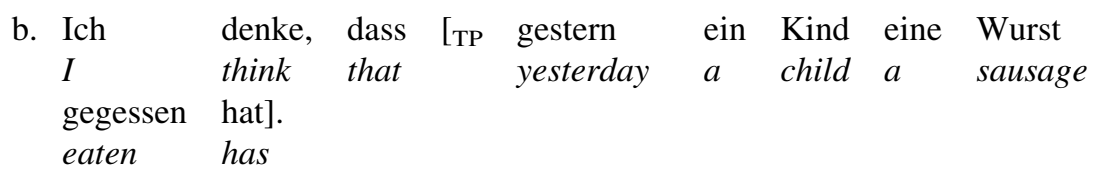

'I think that yesterday, a child ate a sausage.'

c. Ich denke, dass [те ein Kind bestimmt/gestern eine Wurst gegessen hat].

(6) a. Bestimmt hat ein Kind eine Wurst gegessen. definitively has a child a sausage eaten 'Definitively, a child ate a sausage.'

b. Gestern hat ein Kind eine Wurst gegessen. yesterday has a child a sausage eaten

'Yesterday, a child ate a sausage.'

c. Ein Kind hat bestimmt/gestern eine Wurst gegessen.

This privileged access of the left periphery of TP to Spec, CP has been analyzed in terms of non-operator movement to the prefield in Fanselow (2002), an analysis taken up and extended in terms of the 'formal fronting' operation that moves XPs to Spec,CP for purely formal reasons in Frey (2005) (the first position of a clause preceding the verb must be filled). Formal fronting is assumed to be strictly local in nature $^{3}$ and to be triggered by an unspecific EPP or Edge feature in C. It can only target the (hierarchically) closest $\mathrm{XP}^{4}$ in the TP.

Besides subjects and adverbials, given expressions can be placed in the prefield easily (Fanselow 2002; Frey 2005), as illustrated in (7a). To some extent, this is expected under the formal fronting analysis, because given objects can be scrambled to the left edge of TP in German, as in (7b). This allows an interpretation of (7a) in which formal fronting has indeed moved the leftmost category of TP to Spec,CP. ${ }^{5}$

\footnotetext{
3 The formal fronting idea is thus reminiscent of the proposal of Travis (1984) and much subsequent work according to which verb second clauses come in two varieties, viz. TPs and CPs. Cf. Fanselow (2002) and Frey (2005) for a discussion of why these proposals are not general enough. A strict version of the formal fronting model makes the same predictions as the squeezing-in model of Bierwisch (1963). Cf. also Müller (2004) for a different account of the relation between the left edges of TP and CP.

4 But, cf. the discussion in Fanselow and Lenertová (2011) of their examples (49) and (50), which show that the relevant local relation is actually not confined to the closest non-pronominal XP within TP.

${ }^{5}$ However, there is also reason to believe that not all cases of fronting of given expressions can be subsumed under formal fronting in the sense of an operation attracting the closest phrase of the TP. One reason to be skeptical is the observation that other Germanic languages like Dutch, Norwegian, and Swedish allow the fronting of given objects across subjects in non-contrastive, non-emphatic contexts (see Fanselow 2016 for an overview of the fronting possibilities of aboutness topics in the Germanic languages), although given XPs cannot be placed to the left of the subject in TP: Dutch disallows the scrambling of non-contrastive objects to the left of the subject, and Norwegian and Swedish have no scrambling operation at all. This suggests that the fronting of given XPs to the clausal left periphery is quite unrestricted in V2 languages, and cannot be (fully) reduced to formal fronting. However, from an empirical perspective, the privileged access of given XPs to Spec, CP is similarly uncontroversial as in the case of subjects and adverbials, and we will refrain from testing them here.
} 
(7) Ich würde gerne wissen, was dem Briefträger zugestoßen ist—der Nachbar hat erzählt, dass er verletzt ist.

'I would like to know what happened to the postman-the neighbor told me that he is injured.'

a. Den Briefträger hat ein Hund gebissen. the.acc postman has a.nom dog bitten

'A dog has bitten the postman.'

b. Ich fürchte, dass [TP den Briefträger ein Hund gebissen hat]. I fear that the.acc postman a.nom dog bitten has 'I fear that a dog has bitten the postman.'

Another possible way to fill the prefield is A-bar operator movement, triggered by a specific feature of $\mathrm{C}$. A clear example of this is wh-movement, where an element bearing a $w h$-feature is attracted to $\mathrm{Spec}, \mathrm{CP}$. It has been proposed to also analyze the fronting of narrowly focused or contrasted phrases as a kind of A-bar-movement triggered by a focus/contrast feature in $\mathrm{C}$, in parallel to wh-movement (Fanselow 2002; Frey 2006).

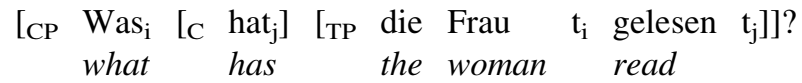

'What has the woman read?'

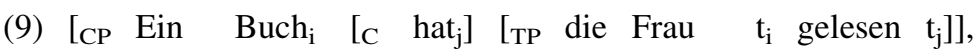
a book has the woman read

keine Zeitschrift.

no magazine

'The woman has read a book, not a magazine.'

Object fronting in a wide-focus context does not appear to fit into any of the subcases of filling the prefield discussed so far. In the context given for (10a), the object must not precede the subject in the middlefield/the TP (cf. 10b), and it is neither discoursegiven nor contrasted with another expression, yet it can be put into the prefield.

Was hat die Frau gemacht?

'What did the woman do?'

a. [CP Ein Buch $_{\mathrm{i}}\left[\mathrm{Cl}_{\mathrm{C}} \mathrm{hat}_{\mathrm{j}}\right]\left[{ }_{\mathrm{TP}}\right.$ sie/ die Frau $\mathrm{t}_{\mathrm{i}}$ gelesen $\left.\left.\mathrm{t}_{\mathrm{j}}\right]\right]$. a book has shel the woman read

'She/The woman has read a book.'

b. *Ich denke dass ein Buch sie/ die Frau gelesen hat. I think that a book shel the woman read has 'I think that she/the woman has read a book.'

For wide-focus object fronting, the empirical picture as well as the theoretical analysis are more controversial than for the fronting of given/contrastive objects. 
For this reason, the empirical focus of this paper and our experiments is on this controversial case.

One way to look at (10) is to see these examples as a case of A-bar operator movement. Under this view, the fronted object should have some identifiable semantic property, in parallel to operator movement triggered by contrast or $w h$-features.

An alternative way to look at the examples in (10) is to subsume them under formal fronting. Under this view, some elements can be skipped over by formal fronting: certain types of subjects do not appear to 'count' when it comes to determining what is the leftmost element in TP that can be placed into the prefield position without any pragmatic load. There are different ideas on what factor is relevant (the prosodic or the syntactic status of the intervening subject), and these ideas go hand in hand with different interpretations of the data, and different empirical predictions.

\subsection{Prosody-sensitive models}

The syntactically least restrictive models assume that the fronting operation itself is unrestricted and prosodic properties account for the presence or absence of intervention effects that a subject may exert on wide-focus object fronting: only accented subjects count as interveners. In other words, in a wide-focus context, the leftmost accented category can go to the prefield by formal fronting. (11a) and (11b) are predicted to be acceptable: the pronoun in (11a) is unaccented; the definite description die Frau in (11b) is discourse-given, hence also deaccented, and thus devoid of intervener-status.

Was hat die Frau gemacht?

'What did the woman do?'

a. [CP Ein Buch ${ }_{\mathrm{i}}\left[\mathrm{C}\right.$ hat $\left._{\mathrm{j}}\right]$ [TP sie $\mathrm{t}_{\mathrm{i}}$ gelesen $\left.\mathrm{t}_{\mathrm{j}}\right]$ ]. a book has she read

'She read a book.'

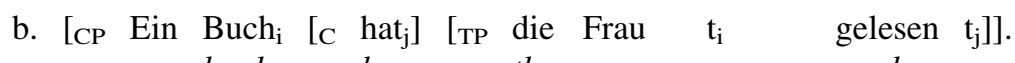
a book has the woman read

'The woman read a book.'

On the other hand, the object cannot cross the subject in (12) by a formal fronting operation, because the subject is not given, hence not deaccented. The sentence can only be generated if the object is fronted by some A-bar-movement operation involving, for example, contrast.

(12) Was ist passiert?

'What happened?'

[CP Ein Buch ${ }_{\mathrm{i}}\left[\mathrm{ll}_{\mathrm{C}} \text { hat }_{\mathrm{j}}\right]_{\text {[TP }}$ eine Frau $\mathrm{t}_{\mathrm{i}}$ gelesen $\left.\mathrm{t}_{\mathrm{j}}\right]$ ]. a book has a woman read

'A woman read a book.'

An example of a prosody-sensitive model is Féry and Drenhaus's (2008) proposal. They explain the difference between $(11 \mathrm{a}, \mathrm{b})$ and (12) by suggesting that object- 
initial broad-focus sentences preferably form a single prosodic phrase. Therefore additional accents besides the one on the object are dispreferred. This explains why (12) may seem degraded: there is a preference for accenting the subject (because it is discourse-new), but at the same time, there is a preference for a single accent on the object, and it is impossible to satisfy both preferences at the same time.

Wierzba (2017) proposes that nuclear stress must fall on the object, as the default preference for nuclear stress on the object in canonical word order carries over to object-initial sentences via a mechanism of prosodic reconstruction. ${ }^{6}$ Therefore all material following the fronted object is deaccented due to postnuclear compression. Like in Féry and Drenhaus's model, the prediction that accented subjects are problematic in object-initial structures thus follows from mapping rules between syntax, information structure, and prosody.

Fanselow and Lenertová (2011) propose a more indirect relation between deaccentuation and intervention effects. They analyze sentences like $(11 \mathrm{a}, \mathrm{b})$ as a case of formal fronting, triggered by an unspecific Edge feature in $\mathrm{C}^{0}$. The difference between (11a, b) and (12) is derived from the assumption that accented phrases need to be linearized early in the course of the derivation. For pairs of accented subjects and objects, order is fixed when these phrases are merged into the syntactic structure. In combination with the assumption that relative ordering statements cannot be altered or removed after they have been established (adopted from Fox and Pesetsky 2005), it follows that an accented object cannot be moved across an accented subject.

\subsection{Syntactic status}

The absence of an intervention effect in (11a) with a pronominal subject can alternatively be explained in terms of syntactic status. The German middlefield is not an unstructured entity, but hosts, at its left edge, a special slot or domain, the Wackernagel position, which is reserved for pronominals. Elements that are placed there arguably cannot move further to $\mathrm{Spec}, \mathrm{CP}$, because they lack phrase status (see Frey 2010, 1421, who proposes that weak pronouns can either appear as XPs or clitics, and in the latter case, they are "attached to the lexically realized head of the C-domain") or because movement from the Wackernagel position to Spec,CP would be improper on different grounds. Since it is conceivable that elements that cannot move to Spec, CP themselves do not exert intervention effects on this kind of movement, intervening subject pronouns would not be able to block object fronting in (11a) even in a wide-focus context. On the other hand, neither given nor new nonpronominal NPs as in (11b) and (12) can occupy the Wackernagel position, so that they should both block object movement in wide-focus contexts.

The two types of models therefore differ in their assessment of the status of (11b). For syntactic-status models, the idea that such sentences could arise in broad focus contexts (as predicted by the prosody-sensitive models) without any semantic

\footnotetext{
${ }^{6}$ The idea that the prosody of sentences involving syntactic movement depends to some extent on the underlying syntactic structure, i.e., that there is 'reconstruction' not only for semantics but also for prosody, has been motivated independently also by, e.g., Bresnan (1971), Selkirk (1995), Korth (2014), and Truckenbrodt (to appear).
} 
or pragmatic restrictions is an illusion: the object must have some special interpretation. There is a strict syntactic intervention effect at work that can be overcome only in an operator movement constellation.

As for the question of what the special interpretation is that can trigger object fronting across a phrase, we will specifically test the proposal that the relevant notion is emphasis. The observation that non-subject-initial sentences in German come with an expressive effect goes back at least to Behaghel (1932, 254-258) and Drach (1939, 26-27), who assume that this sentence type is associated with Erregung 'excitement' or with Affektbeladung 'affect-loadedness', respectively. Frey (2010) implements a similar idea within a generative syntactic framework. Besides formal fronting, an object can also be fronted to the prefield by an A-barmovement operation. In that case, the landing site is the specifier of a different leftperipheral head. If an object is fronted to that position, the interpretation arises that the speaker intends to express that the object is especially high on some salient scale (e.g., especially unexpected). ${ }^{7}$ We will focus on Frey's (2010) implementation of this idea because it makes precise and testable predictions, and we will follow Frey in referring to the relevant meaning component as emphasis.

\subsection{A note on a third kind of approach: topicality}

Another approach to the interaction of object fronting and the type of subject is proposed by Bader et al. (2017). In their corpus study, they observe that pronominal subjects are more likely to occur in the position immediately following the finite verb when the prefield is filled by an object than in the reverse case (finding an object pronoun when the prefield is filled by a subject). They propose that this is due to a correlation between pronominality and topicality, and a preference for placing topics at the left edge of the middlefield (Frey 2004). If the subject is a pronoun and therefore likely to be a topic, this facilitates object fronting because it allows the pronominal subject to appear in the preferred topic position. The predictions of this approach for pronominal subjects converge with both approaches discussed above: it should be easy to front an object across them. For the other types of subjects that we are testing here, the predictions are less clear. Under the view that there is a correlation between topicality and givenness (e.g., in that topics are usually given, Chafe 1976), the expectations would be similar to the prosodic approaches: discourse-given DPs should be easier to cross than new DPs. However, if topicality is understood in Reinhart's (1981) sense of what a sentence 'is about', it is a notion that is orthogonal to discourse-givenness (as argued, e.g., by Krifka 2007). Since topicality in this sense is not a property that we controlled for in our experiments, we will refrain from drawing conclusions about Bader et al.'s topic-based approach in this paper.

\footnotetext{
7 See, e.g., Cruschina (2012) and Bianchi et al. (2016) for related discussion on 'mirative fronting' in Romance.
} 


\subsection{Summary of the predictions}

The predictions of the two model types can be summarized as follows:

(i) The prosody-sensitive models predict that the acceptability of object fronting across a discourse-new subject should be degraded due to its prosodic properties. They do not predict (but are compatible with) degraded acceptability of object fronting across pronouns or discourse-given subjects.

(ii) The syntactic-status models predict that object fronting across a (discoursenew or given) phrase should be degraded when an emphatic interpretation of the object is unavailable. They do not predict (but are compatible with) degraded acceptability of object fronting across a phrase when an emphatic interpretation is available.

Empirical support for the claim that object fronting across discourse-new phrases is more restricted than across a definite pronoun (as both of the approaches predict) has been provided by Féry and Drenhaus (2008) and Fanselow et al. (2008), who found an acceptability difference for OVS sentences with these subject types in wide-focus contexts. Wierzba (2017) compared discourse-given phrases to discourse-new phrases. For these two subject types, similarly low ratings were found in wide-focus contexts. However, as discussed by Wierzba (2017, Chaps. 5.3 and 5.9), there was a potential problem with the materials: the discourse-given phrases were exact repetitions of phrases mentioned in the preceding context. The full repetition of a DP instead of using a pronoun (the repeated name effect; see Gordon and Hendrick 1997) might have interacted in an undesired way with the effect of object fronting. We control for this in the experiments reported here.

In the first two experiments presented in Sect. 3, we will first have a look at the impact of subject type in neutral contexts (neither enforcing nor prohibiting an emphatic interpretation). We aim to replicate the previous findings concerning definite pronouns and discourse-new phrases and to extend the data set to given phrases (including exact repetitions, but also different forms) and indefinite pronouns. This will allow us to assess the predictions of the prosody-sensitive approach: it predicts that discourse-given phrases should pattern with pronouns, because they have similar prosodic properties. The context-dependent predictions of the syntactic-status approach will be addressed in Sect. 4, where we will report the results of experiments in which the factor emphasis is controlled.

\section{First set of experiments: intervening elements}

The prosody-sensitive approach predicts that the crucial factor for the acceptability of wide-focus object fronting should be whether the subject can be deaccented. This depends on both formal and information-structural factors: lexical categories are required to be accented, whereas functional categories, e.g., pronouns (at least monosyllabic ones), are not (see Truckenbrodt 1995; Selkirk 1996); discourse-new phrases need to be accented, whereas phrases that are given, i.e., coreferent with an antecedent in the previous discourse, do not (Akmajian and Jackendoff 1970; 
Schwarzschild 1999). If the prosody-sensitive approach is correct, object fronting should be most degraded when the subject is discourse-new and non-pronominal. It should be more acceptable when the subject is discourse-given and/or pronominal. Since the context used here neither enforces nor excludes an emphatic interpretation of the fronted object, the predictions of the syntactic-status approach cannot be assessed directly. They will be addressed in the experiments in Sect. 4.

The two experiments reported in Sects 3.1 and 3.2 were set up similarly in that the influence of different types of subjects on the acceptability of object fronting was tested. The second one aimed at removing some specific problems contained in the design of the first experiment.

\subsection{Experiment 1: subject type}

\subsubsection{Participants and procedure}

Thirty-six native speakers of German participated in the study. For all experiments reported in this paper, participants were recruited at the University of Potsdam. They received payment or course credits for participation. The study was conducted using an online questionnaire, which was made accessible via the SoSci Survey software (Leiner 2014). Each item was presented on a separate screen, with the target sentence appearing below the context sentence(s). The participants were asked to rate the acceptability of the target sentence in the given context on a scale from 1 (= completely unacceptable) to 7 (= completely acceptable). After the subject had rated an item and clicked on a 'continue' button, the next item appeared on the screen. The 48 items for the current study were intermixed with the same number of fillers/experimental items from other studies. ${ }^{8}$ In sum, 96 stimuli were presented to each participant.

\subsubsection{Design and materials}

The first factor that we manipulated was word order: the object was either in situ (SVO order) or fronted to the prefield (OVS order). The second factor that we manipulated, subject type, had six levels. The subject had one of the following forms: (a) a definite pronoun (er 'he', sie 'she', or es 'it'), (b) a definite DP that was given, i.e., pre-mentioned in the context and repeated in the target sentence (e.g., der Nachbar 'the neighbor'), (c) an epithet-like definite DP that was given, i.e., coreferent with a DP in the context, but it was not identical with it in form (e.g., der Idiot 'the idiot'), (d) a weak indefinite pronoun (wer 'somebody'), (e) an indefinite DP that was new, i.e., it was not pre-mentioned in the context and it introduced a new referent, using the same noun as in condition b (e.g., ein Nachbar 'a neighbor'),

\footnotetext{
${ }^{8}$ The fillers involved various structures with different degrees of acceptability. For example, they included extraposition of DPs (which is degraded for structural reasons) and semantic context-answer mismatches (e.g., contradictory uses of exclusive/additive particles). One of the two other studies from which materials were included concerned the fronting of predicative elements. The other was also concerned with object fronting, but targeted the status of elements following the extraction site rather than intervening material.
} 
(f) an indefinite DP that was new, using the same noun as in condition c (e.g., ein Idiot 'an idiot'). The object was always part of a larger focus: in conditions a-c, the VP was focused, and in conditions $d-f$, the whole sentence was focused. These manipulations resulted in a $6 \times 2$ design (within-subjects, within-items). We constructed 48 items in 12 versions each. ${ }^{9}$ An example of an item set is shown in (13). (13a-f) illustrate the SVO conditions, (13g-1) illustrate the OVS conditions.

(13) Context sentence 1 (present in all items):

Warum riecht es hier so? 'What's that smell?'

Context sentence 2 (following the first context sentence in conditions a-c only):

Was hat der Nachbar gemacht? 'What did the neighbor do?'
a. $\frac{\mathrm{Er}}{h e}$
hat
Würstchen gegrillt. definite pronoun sausages grilled
has

b. Der $\frac{\text { Nachbar hat }}{\text { neighbor has }}$

Würstchen gegrillt. definite DP 1 (repeated)

c. Der Idiot hat sausages grilled

the $\overline{\text { idiot }}$ has

Würstchen gegrillt. definite DP 2 (epithet)

d. Da hat wer sausages grilled

there has

someone sausages grilled

e. Ein $\frac{\text { Nachbar hat }}{\text { neighbor has }}$

Würstchen gegrillt. indef. DP 1 (new) sausages grilled (same noun as in condition $b)$
f. Ein Idiot hat Würstchen gegrillt. indef. DP 2 (new) $\overline{\text { an }} \overline{\text { idiot }}$ has sausages grilled (same noun as in condition c)
g. Würstchen hat er gegrillt. definite pronoun sausages has he grilled
h. Würstchen hat der Nachbar gegrillt. definite DP 1 (repeated) sausages has the neighbor grilled
i. Würstchen hat $\underline{\mathrm{der}}$ Idiot gegrillt. definite DP 2 (epithet) sausages has the idiot grilled
j. Würstchen hat wer gegrillt. indefinite pronoun sausages has someone grilled
k. Würstchen hat ein Nachbar gegrillt. indef. DP 1 (new) sausages has a neighbor grilled
1. Würstchen hat ein Idiot gegrillt. indef. DP 2 (new) sausages has $\overline{\text { an }} \overline{\text { idiot }}$ grilled

'He/the neighbor/the idiot/someone/a neighbor/an idiot has grilled sausages.'

Note that the weak indefinite pronoun wer 'someone' cannot appear in the prefield position, so the locative expletive $d a$ 'there' was used in the prefield in condition $\mathrm{d}$

\footnotetext{
9 We detected that due to an oversight in the construction of the materials, an item was accidentally included twice.
} 
in the SVO series. For convenience, we will nevertheless continue to refer to this condition as 'SVO order'.

\subsubsection{Results}

Prior to analysis, the mean acceptability ratings were transformed to $z$-scores based on all available data from each participant (including fillers). The results are summarized in Table 1 and illustrated in Fig. 1. In both plots in Fig. 1, the same color-coding is used for the different subject types, and it will be retained throughout the paper. The left plot illustrates the mean $z$-scores for each subject type in SVO and OVS order. The relative acceptability of OVS (i.e., the degraded acceptability in comparison to SVO order) is thus represented by the steepness of the line between SVO and OVS order. The right plot presents the same information in a different way, making the relative acceptability more salient: the height of the bars represents the SVO-OVS difference for each subject type. The dotted line shows the mean SVO-OVS difference across all conditions for comparison.

We analyzed the effect of subject type on the relative acceptability of OVS order using a linear mixed model. All linear mixed models reported in this paper were fit following the recommendations for identifying parsimonious models by Bates et al. $(2015 b)^{10}$ using the R package lme4 (Bates et al. 2015a; R Core Team 2016). $P$ values were calculated using the $R$ package lmerTest (Kuznetsova et al. 2017). Sum coding was used for the categorical subject type variable, meaning that each of the six levels was compared to the grand mean. The model results for the interaction of a given level of subject type with the factor word order can be interpreted as expressing whether the SVO-OVS difference at this level was significantly different from the overall mean SVO-OVS difference. The factor word order was coded such that a negative $t$-value indicates that the SVO-OVS difference is smaller than average, and a positive $t$-value indicates that the difference is larger.

The results show a significant interaction with word order for the indefinite pronoun $(t=-2.88, p=0.005)$ and definite DP 2 (epithet) $(t=-7.00$, $p<0.001)$ subject types going in the direction that the SVO-OVS difference is smaller than average, and a marginally significant interaction in the same direction for definite pronoun $(t=-1.95, p=0.051)$. A significant interaction in the opposite direction, i.e., a larger than average SVO-OVS difference, was found for the subject types definite DP 1 (repeated) $(t=2.88, p=0.005)$, new DP $1(t=5.47$, $p<0.001)$, and new DP $2(t=2.71, p=0.007)$.

\footnotetext{
${ }^{10}$ We successively reduced the maximal model by removing terms from the random effect structure that showed signs of overfitting until arriving at a model whose principal components all explain non-zero variance and provide a better fit than the minimal model (including only random intercepts).
} 
Table 1 Mean acceptability (in terms of $z$-scores/original ratings on the 7-point scale) for each condition of Experiment 1, as well as mean SVO-OVS differences; standard deviation in parentheses

\begin{tabular}{|c|c|c|c|c|c|c|}
\hline \multirow[t]{2}{*}{ Subject type } & \multicolumn{3}{|c|}{ Mean acceptability (z-scores) } & \multicolumn{3}{|c|}{ Mean acceptability (7-point scale) } \\
\hline & SVO & OVS & diff. & SVO & OVS & diff. \\
\hline def. pronoun $(e r)$ & $0.92(0.50)$ & $0.09(0.67)$ & 0.84 & $6.39(1.24)$ & $4.82(1.62)$ & 1.56 \\
\hline $\begin{array}{l}\text { def. DP } 1 \text { (repeated) } \\
\text { (der Nachbar) }\end{array}$ & $1.01(0.41)$ & $-0.15(0.67)$ & 1.16 & $6.44(0.99)$ & $4.39(1.54)$ & 2.06 \\
\hline $\begin{array}{l}\text { def. DP } 2 \text { (epithet) } \\
\text { (der Idiot) }\end{array}$ & $0.72(0.67)$ & $0.21(0.79)$ & 0.52 & $6.06(1.41)$ & $5.07(1.56)$ & 0.99 \\
\hline indef. pronoun (wer) & $0.05(0.79)$ & $-0.74(0.71)$ & 0.79 & $4.77(1.71)$ & $3.28(1.69)$ & 1.49 \\
\hline new DP 1 (ein Nachbar) & $0.79(0.68)$ & $-0.58(0.79)$ & 1.36 & $6.18(1.40)$ & $3.65(1.64)$ & 2.53 \\
\hline new DP 2 (ein Idiot) & $0.52(0.69)$ & $-0.63(0.75)$ & 1.14 & $5.71(1.33)$ & $3.59(1.69)$ & 2.11 \\
\hline overall mean & $\varnothing 0.67$ & $\varnothing-0.30$ & $\varnothing 0.97$ & Ø 5.92 & $\varnothing 4.13$ & $\varnothing 1.79$ \\
\hline
\end{tabular}
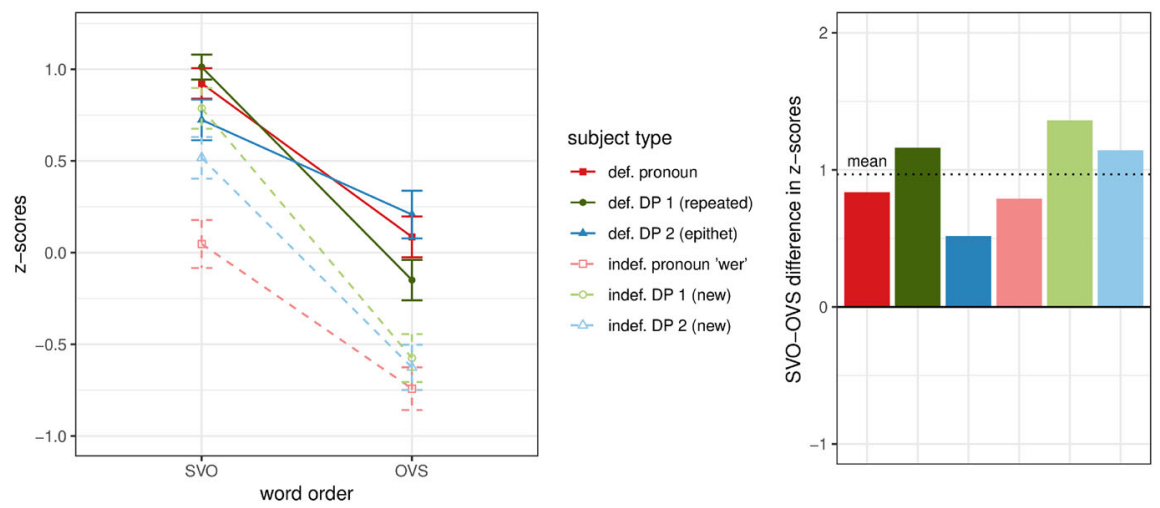

Fig. 1 Mean acceptability in terms of $z$-scores for Experiment 1 (left plot; error bars correspond to 95\% confidence intervals) and mean acceptability difference between SVO and OVS (right plot)

\subsubsection{Discussion}

In all conditions, SVO sentences were rated as more acceptable than their OVScounterparts. This finding is in line with many other studies (see Weskott et al. 2011 for an overview) and can be interpreted in terms of the greater processing difficulty of object-initial sentences, probably due to the greater memory load (Fiebach et al. 2002). Attempts to eliminate this disadvantage of object-initial sentences are only rarely completely successful (cf., e.g., Fanselow et al. 2008; Weskott et al. 2011). In this experiment, the facilitating effect of certain subject types on object fronting thus manifests itself only in decreasing the SVO-OVS acceptability difference, not in reversing the preference. 
Prosody-sensitive approaches to object fronting predict that the discourse-new DPs should show a large SVO-OVS difference, and deaccentable subjects (definite pronoun, indefinite pronoun, epithet, and repeated DP) should show a smaller SVOOVS difference. The results conform to these predictions for the most part: the conditions involving a new DP subject indeed show an above-average SVO-OVS difference, whereas the pronominal conditions and the epithet subject show a belowaverage difference (marginally significant for the definite pronoun). Only the repeated DP condition falls out of the pattern that is predicted by the prosodysensitive hypothesis: although repeated DPs do not need to be accented, they show an above-average SVO-OVS difference in our results (in line with Wierzba's 2017 findings). We will take up this issue again in the discussion of the next experiment.

As for the indefinite pronoun wer, it shows quite low acceptability ratings even in the SVO condition. Thus, there is the concern that the relatively small SVO-OVS difference in this condition might be driven by the fact that a smaller range of the scale was available for the participants below the mean level of the SVO rating to express the acceptability decrease in the object-initial version (although with a mean rating of 3.28 , the absolute rating scores for OVS are not immediately close to the floor level).

On first inspection, the results thus appear to support the hypothesis that deaccented subjects facilitate object fronting, in line with the predictions of the prosody-sensitive approach. However, one might argue that the experiment did not yield fully compelling evidence, on the basis of the following consideration: There could be an unrelated reason for the small size of the SVO-OVS difference for the definite epithetic subjects. In most cases, the epithet was an expressive element like 'the idiot', 'the fool', etc. The high degree of expressivity of this type of subject may have led (some) participants to add an implicit scale to the context, in which, e.g., sausages occupy an extremely low position on food worthy of being grilled (as compared to, say, corncobs or steaks), or in which sausage grilling occupies a fairly low rank in the scale of sensible activities (as compared to, say, sunbathing, tidying up the room, finishing a paper). Some of the examples in the epithetic conditions might thus involve emphasis in Frey's (2010) sense, and could have been licensed as instances of operator movement. This interpretation of the data is supported by the fact that the indefinite epithetic condition (involving the same choice of nouns, e.g., an idiot) also showed an SVO-OVS difference that is smaller than in the general indefinite new subject condition (a neighbor).

While these problems are certainly real, we still observe a clear difference in the acceptability of items involving epithets between the discourse-given version (object fronting penalty of 0.52 in terms of $z$-scores) and the discourse-new one (penalty of 1.36) that is in line with the predictions of the prosody-sensitive approach but unaccounted for in the syntactic-status approach. Since it is implausible that the degree of expressiveness depends on the givenness/newness of the phrase, the difference between the given and new version of the epithets is likely to reflect their prosodic status (or definiteness, see below). In that respect, Experiment 1 still supports the point made above even though there might be a confound related to expressivity.

To be on the safe side, we addressed the potential expressivity confound in a follow-up study, which we report in the following section. 


\subsection{Experiment 2: subject type (follow-up)}

In order to overcome the difficulties in interpreting the results of our first experiment, we constructed a follow-up study that differed from the first one in two respects. First, in order to exclude (or minimize) potential effects of expressiveness on the object in Spec,CP, all expressive epithets were replaced by non-expressive coreferential expressions denoting a superset of the description used in the context sentence. Second, the low acceptability for both the SVO and OVS condition with sentences involving the indefinite pronoun subject wer led us to replace it by the indefinite pronoun jemand, which comes with the further advantage of not being grammatically excluded from the prefield position.

\subsubsection{Participants and procedure}

Forty native speakers of German participated in the study. All of them were undergraduate students at the University of Potsdam, who received payment or course credits for participation. The study was conducted using a pen-and-paper questionnaire. The items were presented below each other. Within each item, the target sentence appeared on a separate line below the context sentence(s), followed by a 1-to-7 scale. The participants were asked to rate the acceptability of the target sentence in the given context on a scale from 1 (= completely unacceptable) to 7 (= completely acceptable). The 40 items for the current study were intermixed with 80 fillers (stemming from studies on exhaustivity, contrastive topics, and extraposition); in sum, each participant rated 120 stimuli.

\subsubsection{Design and materials}

In this experiment, we used a $5 \times 2$ design that was partly between-items: definite subjects were tested with different items than indefinite subjects this time. We constructed 24 items in 6 versions with definite subjects. An example item set (in its SVO conditions) is given in (14). Just as in the first experiment, the subject could either be a definite pronoun, a repeated DP, or a coreferential DP; however, in this experiment, the latter was not expressive or emotionally loaded-it was always a neutral description of the type der Mann 'the man', die Frau 'the woman', etc.

(14) Context (present in all items with definite subjects):

Warum riecht es hier so? Was hat der Nachbar gemacht?

'What's that smell? What did the neighbor do?'
a. $\underline{\operatorname{Er}}$ hat
Würstchen gegrillt.
he has
sausages
grilled
b. Der $\frac{\text { Nachbar hat }}{\text { theighbor has }}$
Würstchen gegrillt. def. DP 1 (repeated)
the neighbor has
the man has
sausages grilled
definite pronoun
'He/the neighbor/the man has grilled sausages.' 
We also constructed 16 items in 4 versions with indefinite subjects. An example item set is given in (15). This time, we tested the indefinite pronoun jemand instead of wer, and only one type of new DP, namely ein Mann 'a man', eine Frau 'a woman', etc. (in line with the definite subjects in the condition coreferential DP). A difference between jemand and wer lies in the fact that only the latter but not the former is excluded from certain stress-requiring positions like the prefield. We will return to the prosodic status of jemand in the discussion section. With the elimination of expressivity, there is no relevant difference between conditions (14b) and (c) when the subject is not given (a neighbor/a man are not expected to differ in their accentuation properties), so that we removed this condition in Experiment 2 and tested only one type of discourse-new DP, as shown in (15).

(15) Context (present in all items with indefinite subjects):

Warum ist es so verqualmt hier? 'Why is the room filled with smoke?'
a. Jemand hat die Brötchen verbrannt. indefinite pronoun someone has the rolls burnt
b. Ein Mann hat die Brötchen verbrannt. new DP $\bar{a} \quad \overline{m a n}$ has the rolls burnt

'Somebody/a man has burnt the rolls.'

\subsubsection{Results}

The results are summarized in Table 2 and illustrated in Fig. 2. Again, the left plot illustrates the mean $z$-scores for each subject type in SVO and OVS order. The right plot presents the SVO-OVS difference for each subject type. The dotted line shows the mean SVO-OVS difference across all conditions for comparison.

Table 2 Mean acceptability ( $z$-scores/original ratings on the 7-point scale) for each condition of Experiment 2, as well as mean SVO-OVS differences; standard deviation in parentheses

\begin{tabular}{|c|c|c|c|c|c|c|}
\hline \multirow[t]{2}{*}{ Subject type } & \multicolumn{3}{|c|}{ Mean acceptability ( $z$-scores) } & \multicolumn{3}{|c|}{ Mean acceptability (7-point scale) } \\
\hline & SVO & OVS & diff. & SVO & OVS & diff. \\
\hline def. pronoun $(e r)$ & $1.14(0.56)$ & $0.11(0.73)$ & 1.03 & $6.60(1.02)$ & $4.68(1.49)$ & 1.93 \\
\hline $\begin{array}{l}\text { def. DP } 1 \text { (repeated) } \\
\text { (der Nachbar) }\end{array}$ & $1.07(0.56)$ & $-0.16(0.69)$ & 1.22 & $6.48(1.05)$ & $4.21(1.36)$ & 2.26 \\
\hline $\begin{array}{l}\text { def. DP } 2 \text { (coreferent) } \\
\text { (der Mann) }\end{array}$ & $0.90(0.64)$ & $-0.19(0.69)$ & 1.09 & $6.17(1.23)$ & $4.12(1.50)$ & 2.05 \\
\hline indef. pronoun (jemand) & $1.12(0.49)$ & $-0.44(0.71)$ & 1.56 & $6.56(0.90)$ & $3.64(1.45)$ & 2.93 \\
\hline new DP (ein Mann) & $0.87(0.74)$ & $-0.60(0.72)$ & 1.47 & $6.12(1.39)$ & $3.33(1.46)$ & 2.79 \\
\hline overall mean & $\varnothing 1.02$ & $\varnothing-0.26$ & $\varnothing 1.28$ & Ø 6.39 & $\varnothing 4.00$ & $\varnothing 2.39$ \\
\hline
\end{tabular}



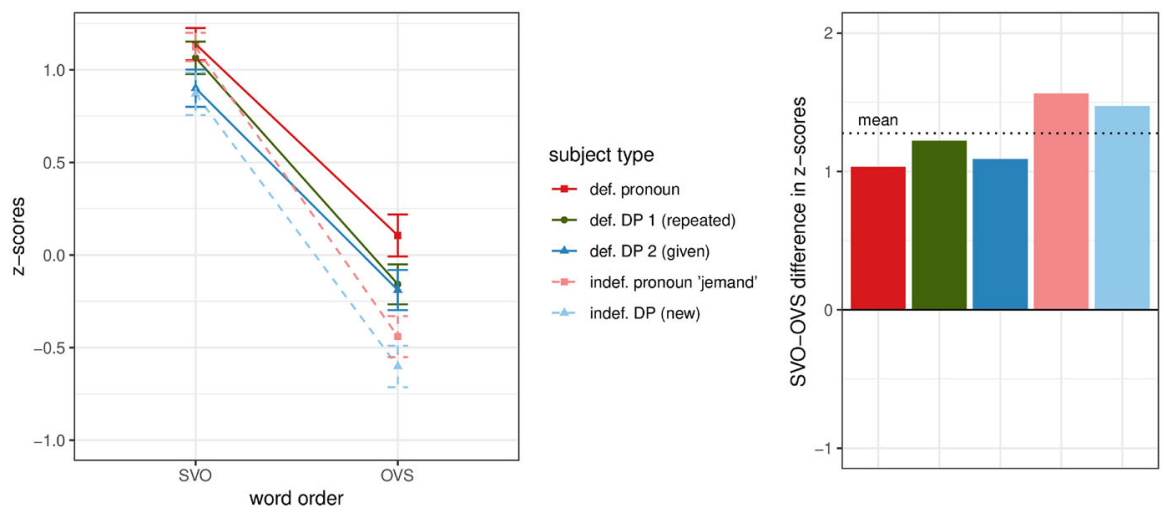

Fig. 2 Mean acceptability in terms of $z$-scores for Experiment 2 (left plot; error bars correspond to $95 \%$ confidence intervals) and mean acceptability differences between SVO and OVS (right plot)

We analyzed the data using a linear mixed model, following the recommendations for identifying parsimonious models. Both factors were sum-coded, as described for the first experiment.

The levels definite pronoun $(t=-4.05 p<0.001)$ and coreferential DP $(t=-3.20, p=0.001)$ significantly interacted with word order: the SVO-OVS difference was smaller than average. For the repeated DP level, the SVO-OVS difference was not significantly different from average $(t=-0.82, p=0.4)$. A significant interaction in the direction of a larger than average SVO-OVS difference was found for the levels new DP $(t=3.25, p=0.001)$ and indefinite pronoun $(t=4.83, p<0.001)$.

\subsubsection{Discussion}

The problematic aspects of the first experiment were avoided in the revised version: the use of the indefinite pronoun jemand (replacing wer) was rated acceptable in subject-initial word order, so the concern about a potentially compressed SVO-OVS difference due to a generally low acceptability does not apply in the second experiment. Also, since no expressive elements like 'the idiot' were used this time, the other potential confound (expressivity) was also avoided.

The major finding of Experiment 2 is that the definite pronoun and the coreferential subject condition show a lower than average SVO-OVS difference. Thus, even after removing a confound triggered by expressive epithets, deaccentable full DPs behave very similarly to definite pronouns. This is compatible with the assumption that accentuation is important for the acceptability of object fronting.

However, two conditions pose a problem for the prosody-sensitive approach. First, for the condition with repeated DPs, the new results confirm the finding of the previous experiment: it is more problematic to cross a repeated DP than a pronoun or a coreferential DP. We conjecture that there might be a repeated name penalty at play (i.e., an acceptability decrease due to the exact repetition of an expression, cf. 
Gordon and Hendrick 1997), which interacts with word order in that it affects the OVS conditions more strongly than the SVO conditions. One might assume that both OVS order and repeated names lead to processing difficulties that often interact in a superadditive way (see, e.g., Hofmeister et al. 2014). We tried to find supporting evidence for this hypothesis in a control experiment (reported in the "Appendix" section), which failed to yield a significant result, however. Therefore, the additional penalty for objects crossing repeated subjects (unexpected for both hypotheses under consideration) remains an open question for future research. Still, the finding that it is easier to cross a repeated DP than a new DP is expected under a prosodysensitive approach.

The crossing of the indefinite pronoun jemand also leads to a strong decline in acceptability. Unfocused functional elements are not necessarily parsed as phonological words and can thus lack word-level stress (Selkirk 1996, 2011), so according to the accent-based crossing hypothesis, it should be easy to cross them, and the result is unexpected under the prosody-sensitive approach. However, the option to remain without stress concerns "in particular the monosyllabic" functional items (Selkirk 2011), and even these have a stress and accent potential-whether they bear stress in a particular sentence or not depends on morphosyntactic and phonological constraints. A better understanding of the particular stress properties of jemand would thus be required in order to evaluate the accent-based approaches in view of the experimental results for this condition. If jemand is in principle able to carry word stress and a phrasal accent, it could be subject to the same information-structural mapping principles as other DPs: deaccentuation might only be licensed if jemand is discourse-given. ${ }^{11}$ This might explain why it behaves very similarly to discourse-new full DPs in our experiment, but further research including auditory materials is needed to confirm this reasoning.

It is also possible that jemand is indeed deaccentable, and it is another property that causes the degraded acceptability when it is crossed. Our results show a split between definite/discourse-given subjects, which can be crossed by objects more easily, and indefinite/discourse-new subjects, for which this is more problematic. This split is predicted by the prosody-sensitive approach for all subject types except indefinite pronouns. They are the only type of subject we tested where indefiniteness/newness does not necessarily coincide with being accented because functional elements can be deaccented even without information-structural licensing (under standard assumptions, with the caveat above). The finding that jemand behaved similarly to the other indefinite/discourse-new phrases that we tested would be compatible with the view that definiteness/givenness plays an even more direct role than assumed by the prosody-sensitive approach.

The specific pattern that we observe does not, however, follow straightforwardly from previously established generalizations about the influence of definiteness on German word order; in particular, it does not follow a definite < indefinite ordering

\footnotetext{
11 Under Schwarzschild's (1999) definition of givenness, the conditions under which the indefinite pronoun jemand 'someone' is given are relatively weak, but not trivially satisfied: it is given if there is an expression in the context that entails that someone exists, which would be satisfied whenever some person has been mentioned.
} 
preference (Lenerz 1977). This rule was proposed for elements within the middlefield, but it is worth considering whether a more general preference along these lines could explain the observed pattern. However, the prediction would go against our observations: we would expect that fronting a definite object across an indefinite subject might be facilitated. In all other cases (fronting an indefinite object across a definite subject, or when both the subject and the object are definite/ indefinite), the fronting operation does not lead to an advantage with respect to the definite $<$ indefinite preference. Our items included both definite and indefinite objects ( 21 out of 48 objects in Experiment 1 were definite, and 18 out of 40 objects in Experiment 2 were definite). Thus, if anything, we would expect to see an overall higher relative acceptability of indefinite subjects, contrary to our findings.

For now, we therefore conclude that we do see a robust effect of givenness/ definiteness in Experiments 1 and 2, which goes in the direction predicted by the prosody-sensitive approach for non-pronominal phrases and definite pronouns, but not for the indefinite pronoun jemand. Determining the reason for this will require further research.

Another potential goal for future research would be to disentangle the factors definiteness and givenness. These properties coincided in our materials, but in principle, one could test DPs that are indefinite, but discourse-given. Our intuition (not necessarily shared by all) suggests that this type of DP does not exert a blocking effect on crossing object movement in wide-focus contexts, as shown in (16).

(16) Was müsste eine Ärztin in dieser Situation tun?

'What would a doctor have to do in this situation?'

Einen Wundverband müsste eine Ärztin in so einer

a.acc wound.dressing must.subj a doctor in such a

Situation anlegen.

situation apply

'A doctor would have to apply a wound dressing in such a situation.'

This condition was not included in our studies and remains to be tested in future work.

\section{Second set of experiments: emphasis}

Syntactic-status approaches to wide-focus fronting predict that fronting across a pronominal subject can be a case of formal fronting and should be possible irrespective of context. Fronting across a full DP, on the other hand, can only be a case of A-bar-movement and should thus only be felicitous under certain interpretative conditions. In particular, Frey (2010) argues that the object needs to be associated with an emphatic interpretation in these cases. Emphasis is understood as an interpretation relative to a set of alternatives that are ranked on a scale, with 
the fronted element occupying an extreme point on the scale. This hypothesis served as a basis for Experiments 3,4 and 5. ${ }^{12}$

In Experiment 3, we compare sentences including elements that express extreme (low/high) points on a scale to neutral sentences lacking such emphatic markers, while subject type is held constant (it is always a given DP).

In Experiment 4, we refine the design further by testing not only contexts that invite an emphatic interpretation and neutral ones, but also contexts that are incompatible with an emphatic interpretation. In addition, we cross the emphasis manipulation with a manipulation of subject type by testing pronominal subjects, given DPs, and new DPs. This makes a more detailed evaluation of the predictions possible.

In Experiment 5, we address the question of whether it is empirically warranted to analyze object fronting across phrases in emphatic contexts as cases of A-barmovement. To this end, we test other kinds of A-bar-movement (including relative clauses and wh-questions) and investigate whether they show a similar pattern. Experiment 5 also serves to test a potential alternative explanation for the observed differences between pronouns and phrases in terms of processing.

\subsection{Experiment 3: emphatic particles}

In Experiment 3, we investigate the influence of emphasis with the help of elements such as $n a$ (signaling that the answer given to the question can be deduced from shared knowledge and is thus very low on a scale of informativity) and denk blo $\beta$ 'just imagine' (signaling that the answer is very surprising and thus very high on a scale of informativity). We compare sentences including such markers to neutral sentences, which are not explicitly marked for a high or low degree of informativity.

At least if the ranking concerns informativity, both endpoints of the scale seem to function in a similar way, since, as Frey $(2010,1422)$ observes, the fronting of a very predictable object seems to be as well-formed as the fronting of a very unpredictable one; Titov (2012, 204-205) reports similar observations for object fronting in Russian. In the case of a highly predictable object, the fronting is often interpreted with an undertone of signaling some annoyance about the fact that a question with an obvious answer was posed at all.

It should be noted that Frey's (2010) model does not predict that object fronting in the neutral condition should be unacceptable, because the context is not incompatible with emphasis on the object. However, there is reason to expect an acceptability difference between the conditions containing expressive markers and the neutral condition: the former make the emphatic interpretation of the object explicit and salient, whereas the latter is merely compatible with such an

\footnotetext{
12 The influence of a related concept (mirativity) on syntactic fronting in German was tested experimentally by Trotzke (2017), who found a strong facilitating effect. Since subject type (pronominal/ non-pronominal) and fronted category (NP, verb, PP) varied in the items, this study is not directly informative for the research questions of this paper.
} 
interpretation. Thus, even though none of the conditions is expected to be completely infelicitous, the presence of the expressive elements should facilitate object fronting and raise its relative acceptability. Frey $(2010,1424)$ argues that a context that invites an emphatic interpretation can even reverse the SVO/OVS preference ("if the question demands that a certain ordering between the answering term and its alternatives is taken into account, the variant with the answering term in the prefield is preferred"). If the emphasis-based model is correct, we thus expect both $n a$ and denk blo $\beta$ to have a facilitating effect on object fronting in comparison to a neutral sentence.

In order to control for a possible influence of the fact that denk blo $\beta$ syntactically constructs with an embedded V2 clause, we also added a condition beginning with quasi-parenthetical ich glaube 'I believe' which also constructs with an embedded V2 clause. The experimental design was completed by a condition with a 'real' syntactic embedding. If one believes that emphasis is an utterance-related phenomenon, it should be less easy to come up with an emphatic reading for a fronted object in a truly embedded complement clause (see, e.g., Wagner 2009 for a similar claim).

\subsubsection{Participants and procedure}

Forty native speakers of German participated in this pen-and-paper questionnaire study. The procedure was the same as described for Experiment 2. The 40 items for the current study were intermixed with 88 fillers/materials from other studies (including materials from studies on exhaustivity and bridging that also involved items with object fronting, as well as materials from another study on extraposition of PPs); in sum, each participant rated 128 stimuli.

\subsubsection{Design and materials}

This experiment had a $5 \times 2$ within-subjects within-items design. We constructed 40 items in 10 versions each. The first factor that we manipulated was again word order (SVO vs. OVS). As a second factor, we manipulated whether the sentence was preceded by an emphatic particle and whether it was embedded. The sentence took one of the following forms: (a) a matrix clause without any particle-we will refer to this type of sentence as the 'neutral' condition and treat it as a baseline in the statistical analysis; (b) a matrix clause preceded by the particle $n a$, which is typically used to express impatience and the attitude that the listener should already know the content of the following utterance; (c) a matrix clause preceded by the phrase denk bloß, which expresses surprise or amazement about the following utterance; (d) a clause embedded under quasi-parenthetical Ich glaube 'I believe'; (e) a truly embedded clause beginning with $X$ sagt ' $X$ says'.

An example item set is shown in (17) for SVO order; in addition, there was a version of each sentence in which the direct object was fronted, resulting in ten conditions. 
(17) Context: Was hat die Studentin gemacht?

'What did the student do?'

a. Die Frau hat eine schwierige Gleichung gelöst. the woman has a difficult equation solved 'The woman solved a difficult equation.' (neutral matrix)

b. $\mathrm{Na}$, die Frau hat eine schwierige Gleichung gelöst. well, the woman has a difficult equation solved 'Well, the woman solved a difficult equation.' (negative emphasis)

c. Denk bloß, die Frau hat eine schwierige Gleichung gelöst. imagine $\overline{\text { just, }}$ the woman has a difficult equation solved 'Just imagine, the woman solved a difficult equation.' (positive emphasis)

d. Ich glaube, die Frau hat eine schwierige Gleichung gelöst. $\bar{I}$ think the woman has a difficult equation solved 'I think that the woman solved a difficult equation.' (embedded under 'glaube')

e. Peter sagt, die Frau hat eine schwierige Gleichung gelöst. $\overline{\text { Peter }} \overline{\text { says }}$ the woman has a difficult equation solved 'Peter says the woman solved a difficult equation.' (embedded under 'says')

Based on the proposals of Frey and Titov, we expect the difference between the SVO and the OVS versions to be smallest for the conditions marked for extreme scale values of informativity ( $b, c<a, d, e)$, and we expect the SVO-OVS difference to be larger for embedded clauses $(d, e>a)$.

\subsubsection{Results}

The results are summarized in the form of $z$-scores in Table 3 and illustrated in Fig. 3.

Table 3 Mean acceptability (in terms of $z$-scores/original ratings on the 7-point scale) for each condition of Experiment 3, as well as mean SVO-OVS differences; standard deviation in parentheses

\begin{tabular}{|c|c|c|c|c|c|c|}
\hline \multirow[t]{2}{*}{ Sentence type } & \multicolumn{3}{|c|}{ Mean acceptability (z-scores) } & \multicolumn{3}{|c|}{ Mean acceptability (7-point scale) } \\
\hline & SVO & OVS & diff. & SVO & OVS & diff. \\
\hline neutral matrix & $0.72(0.57)$ & $-0.03(0.75)$ & 0.75 & $6.09(1.13)$ & $4.59(1.69)$ & 1.48 \\
\hline neg. emphasis $(\mathrm{Na}, \ldots)$ & $0.45(0.66)$ & $0.06(0.72)$ & 0.38 & $5.56(1.52)$ & $4.81(1.66)$ & 0.74 \\
\hline pos. emphasis $($ Denk blo $\beta, \ldots)$ & $0.04(0.85)$ & $-0.22(0.80)$ & 0.25 & $4.76(1.78)$ & $4.25(1.74)$ & 0.51 \\
\hline embedded (Ich glaube, ...) & $0.78(0.56)$ & $-0.16(0.73)$ & 0.94 & $6.16(1.23)$ & $4.34(1.70)$ & 1.82 \\
\hline embedded $(X$ sagt,$\ldots)$ & $0.72(0.53)$ & $-0.33(0.80)$ & 1.05 & $6.06(1.13)$ & $4.03(1.77)$ & 2.04 \\
\hline overall mean & $\varnothing 0.54$ & $\varnothing-0.14$ & $\varnothing 0.68$ & $\varnothing 5.72$ & $\varnothing 4.41$ & $\varnothing 1.32$ \\
\hline
\end{tabular}



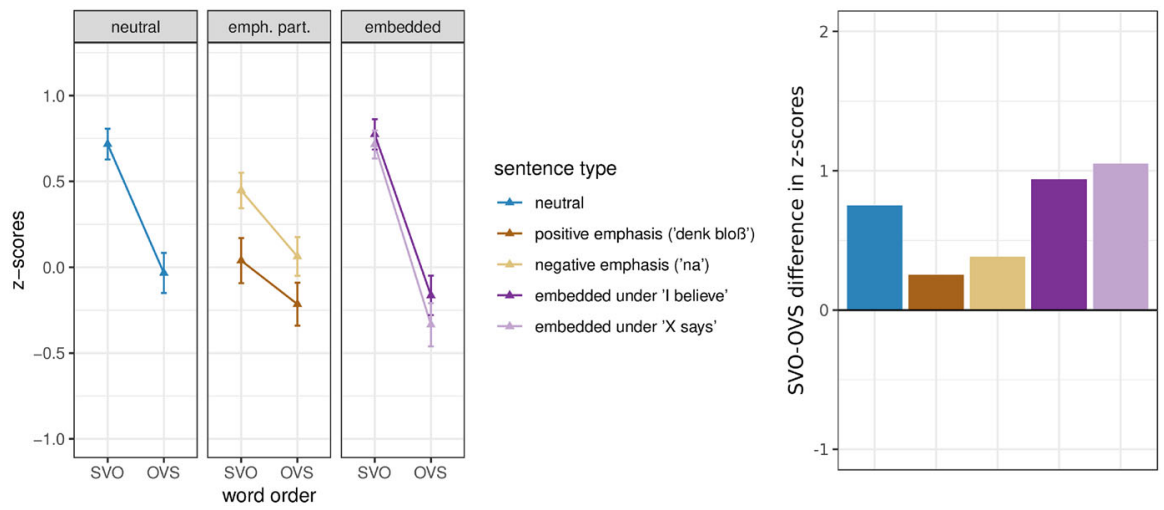

Fig. 3 Mean acceptability in terms of $z$-scores for Experiment 3 (left plot; error bars correspond to 95\% confidence intervals) and mean acceptability difference between SVO and OVS (right plot)

We analyzed the data using a linear mixed model, following the recommendations for identifying parsimonious models. The categorical sentence type variable was coded using treatment coding with the neutral matrix as the baseline, such that each of the four other levels was compared to that condition. The model results for the interaction of the other levels of sentence type with the factor word order can be interpreted as indicating whether the SVO-OVS difference at this level is significantly different from the mean SVO-OVS difference in the neutral matrix condition. The factor word order was sum coded.

The interaction with word order is significant for the conditions involving an expressive particle, in the direction that the SVO-OVS difference is smaller than in the neutral matrix condition when a particle is present $(\mathrm{Na}, \ldots: t=-3.49$, $p<0.001$, Denk bloß, ...: $t=-4.94, p<0.001)$. For the condition involving embedding, a significant interaction with word order in the opposite direction was found, i.e., the SVO-OVS difference was larger than in the baseline condition (embedding under Ich glaube, $\ldots: t=1.99, p=0.047$; embedding under $X$ sagt,$\ldots$ : $t=2.96, p=0.004)$.

\subsubsection{Discussion}

The addition of a particle signaling extreme values of informativity led to a significant reduction of acceptability difference between the SVO and OVS conditions, irrespective of whether a low or a high informativity status was signaled. This reduction is driven by an acceptability decrease of the SVO conditions rather than an acceptability increase of the OVS conditions.

As for the embedded conditions, the results are in line with the expectations: given that emphasis/expressivity is an utterance phenomenon, we do not expect it to influence the syntax of embedded clauses in the same way as matrix clauses. The increase of the SVO-OVS acceptability difference in embedded clauses could thus be interpreted as the unavailability of emphasis as a facilitating factor, whereas it is not excluded in the neutral matrix clause. 
However, the interpretation of the results will be in need of re-evaluation in view of partly contradictory results from Experiment 4. In Sect. 5, we will pursue the question of whether register might have acted as a confounding factor here, and we will report supporting evidence for this conjecture.

\subsection{Experiment 4: interaction between emphasis and subject type}

Experiment 4 aims to test further predictions of the syntactic-status approach. Again, we focus on particular predictions of Frey's (2010) implementation of this idea. Whereas Experiment 3 only compared emphatic sentences to neutral ones, Experiment 4 also includes sentences that are explicitly incompatible with an emphatic interpretation. For the latter, the syntactic-status approach predicts that object fronting should only be possible if the crossed subject is a pronoun, but infelicitous if the subject is a phrase. To test this predicted interaction between context and subject type, we included different subject types again, similar to Experiments 1 and 2 .

Identifying contexts in which an emphatic interpretation is truly excluded is challenging. In constructing our experiment, we followed a suggestion by Frey (2010, 1426), who proposes constructing non-emphatic contexts by adding the assertion that the uttered proposition is actually not worth noting-neither in a positive nor in a negative way. ${ }^{13}$

The predictions of the prosody-sensitive approach, which were tested in Experiments 1 and 2, also hold for Experiment 4: they predict that wide-focus object fronting across discourse-new XP subjects should be degraded (irrespective of emphasis).

\subsubsection{Participants and procedure}

Fifty-four native speakers of German participated in this online questionnaire study. They received payment or course credits for participation. The procedure was the same as for Experiment 1 . The 36 items for the current study were intermixed with fillers/materials from other studies (including materials on discontinuous noun phrases); in sum, 98 stimuli were presented to each subject.

\subsubsection{Design and materials}

We re-used the materials from the first two experiments, but limited the factor subject type to three levels, which are sufficient to distinguish the predictions of the models: definite pronoun, given DP, and new DP. In addition, we manipulated emphasis by extending the context. In the 'emphasis-supporting' condition, we added a sentence like Kannst du dir das vorstellen? 'Can you imagine?', expressing surprise or amazement. In the 'emphasis-excluding' condition, we added a sentence

\footnotetext{
13 We thank an anonymous reviewer for the suggestion to use this method.
} 
like Ach, nicht der Rede wert. 'Eh, it's not worth mentioning.', expressing that the answer is not special in a positive nor negative way. In order to keep the length, format, and register of all conditions comparable, we also added a sentence in the 'neutral' condition. It was always a sentence that neither supported nor excluded an emphatic interpretation, e.g., Das kann ich dir sagen. 'I can tell you that.' The third manipulated factor was again word order (subject-initial vs. object-initial), resulting in a (within-subjects within-items) $3 \times 3 \times 2$ design. We constructed 36 items in 18 versions each. An example item set (with subject-initial order) is shown in (18).

(18) Context: Warum riecht es hier so? (Was hat der Nachbar gemacht?)

'What's that smell? What did the neighbor do?'

a. Das kann ich dir sagen. Er/der Mann/ein Mann hat

that can I you tell. Helthe man/a man has

Würstchen gegrillt.

sausages grilled

'I can tell you that. He/the man/a man grilled sausages.' (neutral)

b. Kannst du dir das vorstellen? Er/der Mann/ein Mann hat

can you yourself that imagine? He/the man/a man has

Würstchen gegrillt!

sausages grilled

'Can you imagine? He/the man/a man grilled sausages!'

(emphasis supported)

c. Ach, nicht der Rede wert. Er/der Mann/ein Mann hat

eh not the speech worth. He/the man/a man has

Würstchen gegrillt.

sausages grilled

'Eh, it's not worth mentioning. He/the man/a man grilled sausages.'

(emphasis excluded)

\subsubsection{Results}

The results are summarized in Table 4 and illustrated in Fig. 4.

The factor word order was sum coded. Subject type was treatment coded with definite pronoun as the baseline. Emphasis was treatment coded with neutral as the baseline. We analyzed the data using a linear mixed model, following the recommendations for identifying parsimonious models. The SVO conditions of two items were excluded due to typos.

A significant three-way interaction between word order, subject type, and emphasis was found $(t=1.99, p=0.048)^{14}$ at the levels emphasis excluded/given $D P$, going in the direction that the difference between definite pronoun and given

\footnotetext{
${ }^{14}$ It has to be noted that this effect is at the border of significance; whether $p<0.05$ depends on the details of the statistical model. E.g., in a linear mixed model with random intercepts and no random slopes, the effect is only marginally significant: $t=1.92, p=0.055$. Replication of this experiment would therefore be desirable in future research.
} 
Table 4 Mean acceptability (in terms of $z$-scores/original ratings on the 7-point scale) for each condition of Experiment 4, as well as mean SVO-OVS differences; standard deviation in parentheses

\begin{tabular}{|c|c|c|c|c|c|c|c|}
\hline \multirow[t]{2}{*}{ Emphasis } & \multirow[t]{2}{*}{ Subject type } & \multicolumn{3}{|c|}{ Mean acceptability ( $z$-scores) } & \multicolumn{3}{|c|}{ Mean acceptability (7-point scale) } \\
\hline & & SVO & OVS & diff. & SVO & OVS & diff. \\
\hline neutral & def. pronoun & $0.89(0.53)$ & $0.15(0.70)$ & 0.74 & $6.13(1.15)$ & $4.67(1.72)$ & 1.46 \\
\hline neutral & given DP & $0.77(0.63)$ & $-0.01(0.69)$ & 0.78 & $5.93(1.41)$ & $4.38(1.60)$ & 1.55 \\
\hline neutral & new DP & $0.88(0.55)$ & $-0.36(0.81)$ & 1.24 & $6.13(1.15)$ & $3.75(1.75)$ & 2.38 \\
\hline supported & def. pronoun & $0.76(0.59)$ & $0.00(0.72)$ & 0.75 & $5.91(1.30)$ & $4.44(1.74)$ & 1.47 \\
\hline supported & given DP & $0.77(0.62)$ & $-0.14(0.67)$ & 0.90 & $5.94(1.38)$ & $4.12(1.58)$ & 1.81 \\
\hline supported & new DP & $0.59(0.69)$ & $-0.51(0.82)$ & 1.10 & $5.57(1.54)$ & $3.41(1.81)$ & 2.16 \\
\hline excluded & def. pronoun & $0.54(0.66)$ & $-0.01(0.72)$ & 0.54 & $5.51(1.41)$ & $4.40(1.65)$ & 1.11 \\
\hline excluded & given DP & $0.58(0.65)$ & $-0.36(0.71)$ & 0.94 & $5.59(1.36)$ & $3.69(1.74)$ & 1.91 \\
\hline excluded & new DP & $0.35(0.78)$ & $-0.71(0.73)$ & 1.06 & $5.15(1.71)$ & $3.06(1.66)$ & 2.09 \\
\hline overall mean & & $\varnothing 0.68$ & $\varnothing-0.22$ & $\varnothing 0.90$ & $\varnothing 5.76$ & Ø 3.99 & $\varnothing 1.77$ \\
\hline
\end{tabular}
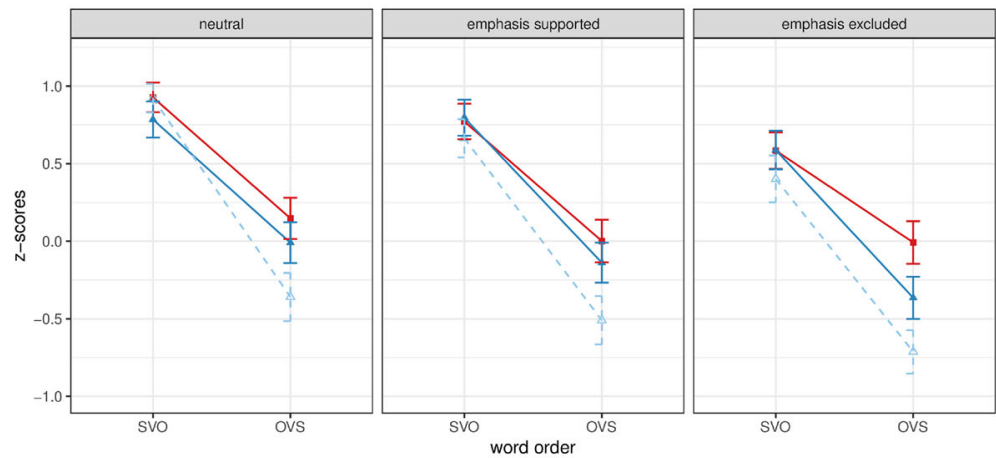

subject type

$\rightarrow$ def. pronoun

$\leftarrow$ def. DP (given)

$-\quad$ indef. DP (new)
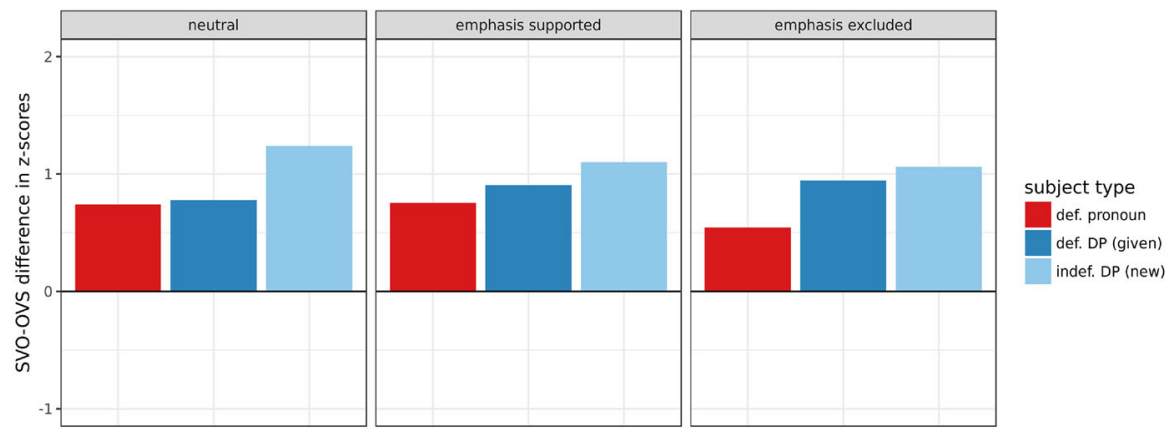

Fig. 4 Mean acceptability in terms of $z$-scores for Experiment 4 (first row of plots; error bars correspond to $95 \%$ confidence intervals) and mean acceptability difference between SVO and OVS (second row of plots) 
DP is larger in a context that excludes an emphatic interpretation than in a neutral context.

\subsubsection{Discussion}

For the 'neutral' context, Experiment 4 by and large replicates the findings of Experiments 1 and 2: there is a clear acceptability difference between the crossing of a discourse-new subject on the one hand, and a pronominal or discourse-given subject, on the other.

The context that excludes an emphatic interpretation differs significantly from the neutral context: the difference between pronouns and discourse-given DPs is larger when no emphatic interpretation is possible. In contrast, the difference between pronouns and discourse-new DPs remains constant. A possible interpretation of this pattern is that crossing a discourse-new DP is difficult on prosodic grounds, in line with the predictions of the prosody-sensitive approach: a discoursenew full DP needs to be accented, and if this poses a problem for movement across it, it should always be relatively degraded. In contrast, pronouns and discoursegiven DPs do not have to be accented and thus do not pose a problem for movement across them.

As for discourse-given DPs, they behave like pronouns in the neutral context (which does not exclude an emphatic interpretation), but like discourse-new DPs in the context that excludes an emphatic interpretation. A possible explanation for this is that the core idea of the syntactic-status approach is correct: pronouns do not act as interveners for Formal Fronting and can therefore be crossed in any context; but crossing an XP is only possible via A-bar-movement, which in turn is only possible if an emphatic interpretation is available. In the context that excludes an emphatic interpretation, fronting is most acceptable across a pronoun, and degraded across a non-pronominal subject irrespective of prosody/discourse status. Acceptability ratings in this domain are thus in line with the predictions made by the syntacticstatus approach.

One has to conclude that the description of object fronting must take recourse to both syntactic and prosodic factors: when emphasis is fully excluded, only pronominals can be crossed over easily, but when an emphatic interpretation is possible, the predictions of the prosody-sensitive approach are fulfilled.

To make the contribution of the prosodic and syntactic factors to the observed pattern more precise and testable in future experiments, we ran another linear mixed model with independent variables that represent the restrictions predicted by the different theories in a more direct way. For this post hoc analysis, we annotated all conditions in which a discourse-new phrase is crossed as containing a prosodyviolation, and all conditions in which any phrase (given or new) is crossed while an emphatic interpretation is excluded as containing a syntax-violation. In addition, we also included a variable representing the general penalty for using an object-initial structure. With these specifications, we find the following estimates for the severity of each violation: using an object-initial structure significantly $(t=12.65$, 
$p<0.001)$ decreases acceptability, by 0.71 points in terms of $z$-scores; crossing a discourse-new phrase additionally significantly $(t=5.40, p<0.001)$ decreases acceptability, by $0.43 z$-scores; crossing a phrase in an emphasis-excluding context additionally significantly $(t=5.26, p<0.001)$ decreases acceptability, by $0.36 z-$ scores. The interaction between the prosodic and syntactic restriction did not reach a significant level $(t=0.89, p=0.38)$. In relative terms, the prosodic violation increased the acceptability difference between SVO and OVS order by the factor 1.6 in our experiment, and the syntactic violation increased the difference by the factor 1.5.

The results for the emphasis-supporting condition are less clear-cut and stand in contrast to the results of Experiment 3. In Experiment 3, we found a reduction of the SVO-OVS acceptability difference for the two emphatic contexts (with emphatic elements) in comparison to the neutral context. In Experiment 4, we did not see this general difference between the emphatic context and the neutral one-no significant difference was found between the two. We will address the tension between the two experiments in Sect. 5, where we will argue that the factor register might have confounded the results of Experiment 3.

The fact that there are differences between the subject types (at least between pronoun and discourse-new DP) also in the emphasis-supporting context implies that prosodic constraints on movement are at play here as well. Under a syntacticstatus approach without additional assumptions, no acceptability differences between the subject types would be expected here, since a derivation in terms of A-bar-movement is available irrespective of subject type. This further supports the view that both syntactic and prosodic factors influence the acceptability of widefocus object fronting. For both types of factors, this concerns the degree to which OVS is degraded in comparison to SVO; at least in the way that we operationalized the factors in our experiments, neither of them makes OVS as acceptable as SVO.

\subsection{Experiment 5: comparing object fronting in emphasis-compatible contexts to operator movement}

Experiment 4 yielded a data pattern that seems to require that both the constraints of a prosody-sensitive approach and those of a syntactic-status approach must be invoked for a complete account of German object fronting: contexts compatible with emphasis display a prosody-sensitive pattern of acceptability, whereas differences between pronoun and phrase matter in contexts that are incompatible with emphasis.

According to the syntactic-status model, the latter effect arises because movement to the left periphery that crosses a full syntactic phrase has to be analyzed as an instance of emphasis-triggered A-bar-movement, in parallel to what is usually assumed for operator movement in $w h$-clauses or relative clauses. In Experiment 5, we aim to test whether assuming a parallel analysis for cases of emphasis-related movement and other cases of operator movement is warranted empirically. If these cases indeed involve the same type of movement operation, we should see a similar pattern with respect to different kinds of intervening subjects. The particular pattern that we are testing is the difference between a subject pronoun 
and a given DP. Recall that Experiment 4 showed a reduced difference between these subject types in emphasis-compatible OVS clauses (in comparison to nonemphatic ones). The same effect (reduced difference between these subject types) should also be found for object $w h$-clauses and object relative clauses, if they are instances of the same kind of movement operation.

Additional motivation for comparing relative clauses and wh-questions comes from work on intervention effects in A-bar-movement. There is experimental research that suggests that object relative clauses are easier to process and understand when the subject in the relative clause "lacks a lexical NP restriction", i.e., when it is a pronoun (Friedmann et al. 2009). Friedmann et al. explain this observation in terms of the idea that intervening elements in A-bar-dependencies are unproblematic when they are of a different syntactic/semantic type than the moved constituent. The question is whether this effect is also reflected in an acceptability rating task like the one we are using here. If so, there would be an alternative interpretation for the special status of pronominal subjects in Experiment 4.

\subsubsection{Participants and procedure}

Thirty-two native speakers of German took part in this online questionnaire study. They received payment or course credits for participation. The procedure was the same as for Experiment 1 . The 30 items for the current study were intermixed with fillers/materials from other studies (including materials on idiomatic verb phrases and on discontinuous noun phrases); in sum, 86 stimuli were presented to each subject.

\subsubsection{Design and materials}

The materials from Experiment 4 were used again, but we extended the range of tested structures to SVO (broad focus), OVS (broad focus), OVS (narrow focus), relative clause, and $w h$-question. In contrast to the previous experiments, it was not possible to construct minimal pairs of subject-initial/object-initial structures for each of the conditions because the choice of the fronted element is not optional in the case of relative clauses and $w h$-questions. For this reason, we will exceptionally not compare relative acceptability (SVO-OVS difference), but the absolute acceptability of OVS order here. We nevertheless included a canonical subjectinitial structure at least for the broad focus case to make sure that there was no independent reason for an acceptability difference between definite pronoun and definite DP, and that any difference that we found in the object-initial structures was indeed movement-related. To keep the number of conditions manageable, we only retested two of the subject types, namely the definite pronoun and the definite/given DP. All structures included one of the emphasis-excluding markers that were also used in Experiment 4, e.g., Ach, nicht der Rede wert 'Eh, it's not worth mentioning'. This was done to make sure that there is no implicit emphatic interpretation that 
would independently license the left-peripheral movement. An example item set is illustrated in (19).

(19) a. Warum riecht es hier so? Was hat der Nachbar gemacht?

'What's that smell? What did the neighbor do?'

Ach, nicht der Rede wert. Er/der Mann hat Würstchen gegrillt. eh not the speech worth. He/the man has sausages grilled

'Eh, it's not worth mentioning. He/the man grilled sausages.' (broad foc SVO)

b. Warum riecht es hier so? Was hat der Nachbar gemacht?

'What's that smell? What did the neighbor do?'

Ach, nicht der Rede wert. Würstchen hat er/der Mann gegrillt. eh not the speech worth sausages has he/the man grilled

'Eh, it's not worth mentioning. He/the man grilled sausages.' (broad foc OVS)

c. Warum riecht es hier so? Hat der Nachbar etwa was gegrillt?

'What's that smell? Did the neighbor grill something?'

Ach, nicht der Rede wert. Würstchen hat er/der Mann gegrillt. eh not the speech worth sausages has he/the man grilled

'Eh, it's not worth mentioning. He/the man grilled sausages.' (narrow foc OVS)

d. Warum riecht es hier so? Was hat der Nachbar gemacht?

'What's that smell? What did the neighbor do?'

Ach, nicht der Rede wert. Das kommt von den Würstchen, eh not the speech worth that comes from the sausages

die er/der Mann gegrillt hat.

which he/the man grilled has

'Eh, it's not worth mentioning. It's because of the sausages that he/the man grilled.'

(object relative clause)

e. Warum riecht es hier so? - Ach, nicht der Rede wert. Das kommt vom Barbecue des Nachbarn.

'What's that smell? - Eh, it's not worth mentioning. It's because of the neighbor's barbecue.'

Was hat er/der Mann denn gegrillt?

what has he/the man PART grilled

'What did he/the man grill?' (object wh-question)

The first two structures SVO/OVS (broad focus) were identical to two of the 'emphasis excluded' conditions tested in Experiment 4. For these conditions with broad focus we expect a replication of the pattern, viz. an advantage for the definite pronoun subject in OVS sentences.

Recall from Experiment 4 that the difference between the two subject types was smaller when an emphatic interpretation was possible. If it is correct to analyze emphasis-related movement parallel to other kinds of A-bar-movement, we should also see a smaller difference between the subject types for the relative clause and the 
wh-question, which uncontroversially involve A-bar-movement. For narrowly focused phrases, Frey (2010) assumes that they can only undergo A-bar-movement if they have an emphatic interpretation. Since an emphatic interpretation would contradict the provided context just like in the broad focus case, no difference between narrow and broad focus is expected under this account.

If the processing-related advantage of intervening pronouns over full DPs found by Friedmann et al. (2009) translates to a facilitating effect on acceptability, then we would expect to find an acceptability difference between the subject types in relative clauses and wh-questions, even if it does not constitute a syntactic problem to cross a DP in these cases.

\subsubsection{Results}

The results are summarized in Table 5 and illustrated in Fig. 5.

We analyzed the data using a linear mixed model, following the recommendations for identifying parsimonious models. Subject type was treatment-coded with pronoun as the baseline. Construction was treatment-coded with broad focus OVS as the baseline. The factor subject type interacted significantly with the factor construction in the case of the object wh-question $(t=2.32, p=0.02)$; i.e., the acceptability difference between pronoun and DP was significantly different than in broad focus OVS. A marginally significant interaction was found for the object relative clause $(t=1.74, p=0.08)$. No significant interaction was found for broad focus $\operatorname{SVO}(t=0.97, p=0.34)$ and narrow focus OVS $(t=1.00, p=0.32)$.

Table 5 Mean acceptability (in terms of $z$-scores/original ratings on the 7-point scale) for each condition of Experiment 5; standard deviation in parentheses

\begin{tabular}{llll}
\hline Construction & Subject type & \multicolumn{2}{l}{ Mean acceptability } \\
\cline { 3 - 4 } & & $z$-scores & 7-point scale \\
\hline broad focus SVO & def. pronoun & $0.64(0.73)$ & $5.52(1.70)$ \\
broad focus SVO & given DP & $0.54(0.75)$ & $5.38(1.74)$ \\
broad focus OVS & def. pronoun & $0.38(0.73)$ & $5.04(1.82)$ \\
broad focus OVS & given DP & $0.13(0.74)$ & $4.57(1.80)$ \\
narrow focus OVS & def. pronoun & $0.16(0.74)$ & $4.68(1.79)$ \\
narrow focus OVS & given DP & $0.03(0.72)$ & $4.38(1.77)$ \\
object relative clause & def. pronoun & $0.19(0.89)$ & $4.68(2.00)$ \\
object relative clause & given DP & $0.17(0.79)$ & $4.71(1.79)$ \\
object $w h$-question & def. pronoun & $0.35(0.95)$ & $4.97(2.03)$ \\
object $w h$-question & given DP & $0.47(0.81)$ & $5.28(1.83)$ \\
overall mean & & $\varnothing 0.31(0.81)$ & $\varnothing 4.92(1.86)$ \\
\hline
\end{tabular}




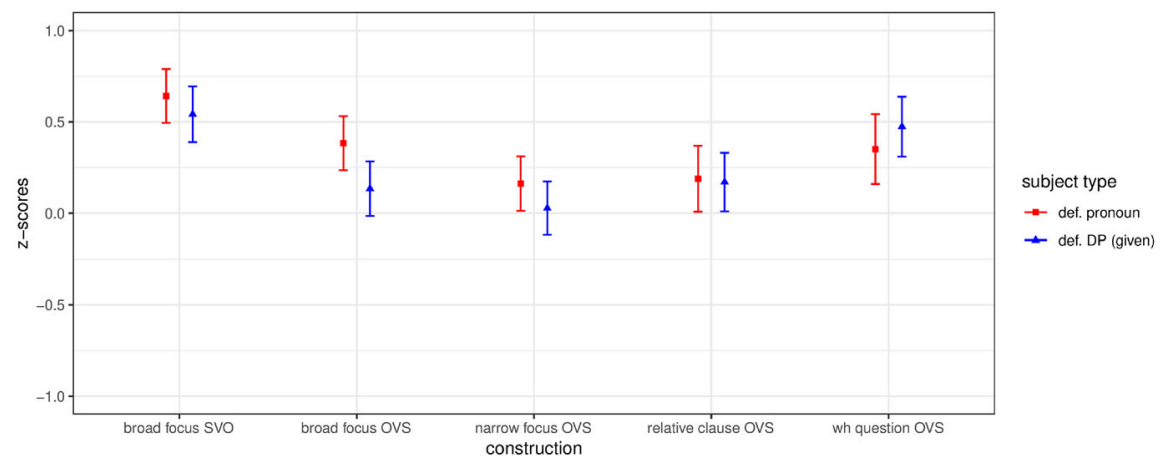

Fig. 5 Mean acceptability in terms of $z$-scores for Experiment 5. Error bars correspond to $95 \%$ confidence intervals

\subsubsection{Discussion}

In Experiment 4, we found that object-initial sentences under broad focus behave differently when an emphatic interpretation is excluded than when it is possible: only when an emphatic interpretation is impossible do we see a clear acceptability difference between a definite pronoun and a DP as the subject. The difference is smaller or non-existent when an emphatic interpretation is possible. Here, we see a similar relation between the non-emphatic broad focus condition and the whquestion: when comparing these conditions, there is a significant interaction between construction and subject type, in the same direction that was observed in the emphatic contexts in Experiment 4. This finding is compatible with the idea that emphasis-related movement is a kind of operator movement, as it shows effects similar to wh-movement; in both cases, it becomes easier to cross a DP subject than it is in the absence of emphasis or a wh-operator.

In the relative clause, we do not see an advantage for the pronominal over the DP subject, either. In comparison to the declarative broad focus construction, the difference did not reach significance (in contrast to the wh-question), which might be due to too low statistical power. The observed trend is compatible with the idea that it is easier to cross DPs in instances of operator movement. The lack of a difference between pronoun and DP furthermore suggests that the processing advantage of pronouns over DPs in relative clauses, which was found in previous studies, did not manifest itself in our acceptability ratings. This supports the view that the differences between the subject types that we do observe (especially in the non-emphatic broad focus condition) are not reducible to processing effects, but reflect grammatical restrictions.

As for narrow focus, according to Frey (2010), crossing a DP should only be possible if an emphatic interpretation is possible, no different from broad focus. In our results, narrow (non-emphatic) focus shows a numerically smaller difference between pronoun and DP than broad focus, but the conditions do not differ in a statistically significant way; no clear conclusion can be drawn about this case. 
In sum, the differences and trends observed in Experiment 5 are overall compatible with the assumption that not just emphasis-related movement, but operator movement in general makes it easier to cross DPs (and therefore diminishes the difference between a pronoun and a DP subject in our experiments).

\section{Third set of experiments: register}

The two final experiments to be reported here address a question arising in connection with Experiment 3, in which we tested the influence of emphasis on object fronting. As pointed out to us by Radek Šimík (p.c.), there is an alternative explanation for the improvement of object fronting that we found in the two conditions with overt informativity marking. The use of $n a$ and denk blo $\beta$ not only signals extreme values of informativity, but also classifies the sentence as belonging to an informal register. The choice of the marked construction can also be registerrelated, so that Experiment 3 might involve a confound. The following experiments were carried out to control for this possibility. The results are also relevant for a reevaluation of Experiments 1 and 2, where we speculated that the higher acceptability of object fronting across epithets like the idiot in comparison to DPs like the man might be due to expressiveness; alternatively, it might be reduced to register. The register confound being present in Experiment 3, but not (or to a lesser extent-we will return to this) in Experiment 4 might also explain the diverging results that we found for the comparison between highly emphatic and neutral sentences.

\subsection{Experiment 6: comparing emphatic particles to hesitation}

In Experiment 6, we address the question of whether there is an alternative explanation for the results of Experiment 3 in terms of register. We took over the neutral condition and one of the emphatic conditions ( $n a$, signaling very low informativity) from Experiment 3 and introduced a third condition in which the utterance was preceded by the hesitation marker $\ddot{a} h$ 'er'. This marker is unrelated to emphasis but signals that the utterance comes from an informal, spoken register. If register plays no role in the licensing of object fronting, then the relative acceptability of object fronting should be higher for the emphatic conditions than for both the neutral and the informal conditions. If register does play a role, then both the emphatic and the informal particle should facilitate object fronting.

\subsubsection{Participants and procedure}

Twenty-seven native speakers of German participated in this online questionnaire study. The procedure was the same as for Experiment 1 . The 18 items for the current study were intermixed with 48 fillers/materials from other studies (including the 'repeated name experiment', which is reported in the "Appendix" section); in sum, each participant rated 66 stimuli. 


\subsubsection{Design and materials}

Using a $2 \times 3$ design, we investigated whether an indication of informal register interacts with word order in the same way as emphasis. The materials were based on the items from Experiment 3. Like in that experiment, we manipulated word order (SVO vs. OVS) and sentence type. We adopted two levels of sentence type from Experiment 3: neutral and emphatic particle ' $\mathrm{Na}, \mathrm{.}$ ' in order to be able to relate the new results to those from the previous experiment. As a third level, we introduced hesitation, which was indicated by $\ddot{A} h, \ldots$ 'Er, ...' at the beginning of the sentence. We assume that it indicates an informal and spoken mode of speech, without adding an emphatic connotation.

An example item set is shown in (20) for SVO order; an OVS version was also constructed for each level of sentence type, resulting in 6 conditions.

\section{Context: Was hat die Studentin gemacht? \\ 'What did the student do?'}

a. Die Frau hat eine schwierige Gleichung gelöst. neutral matrix the woman has a difficult equation solved

b. Na, die Frau hat eine schwierige Gleichung gelöst. emphasis well, the woman has a difficult equation solved

c. $\underline{\text { Äh}}$, die Frau hat eine schwierige Gleichung gelöst. hesitation $\overline{\text { well, }}$, the woman has a difficult equation solved '(-/Well/Er) The woman solved a difficult equation.'

\subsubsection{Results}

The results are summarized in Table 6 and illustrated in Fig. 6.

We analyzed the data using a linear mixed model, following the recommendations for identifying parsimonious models. Treatment coding was used for the sentence type variable, with hesitation $(\ddot{A} h, \ldots)$ as the baseline. A significant interaction with word order was found in comparison to the neutral sentence type

Table 6 Mean acceptability (in terms of $z$-scores/original ratings on the 7-point scale) for each condition of Experiment 6, as well as mean SVO-OVS differences; standard deviation in parentheses

\begin{tabular}{|c|c|c|c|c|c|c|}
\hline \multirow[t]{2}{*}{ Sentence type } & \multicolumn{3}{|c|}{ Mean acceptability (z-scores) } & \multicolumn{3}{|c|}{ Mean acceptability (7-point scale) } \\
\hline & SVO & OVS & diff. & SVO & OVS & diff. \\
\hline neutral & $0.42(0.72)$ & $-0.43(0.76)$ & 0.85 & $5.74(1.46)$ & 4.29 (1.67) & 1.45 \\
\hline emphasis $(N a, \ldots)$ & $0.08(0.66)$ & $-0.39(0.75)$ & 0.47 & $5.11(1.58)$ & $4.36(1.58)$ & 0.75 \\
\hline hesitation $(\ddot{A} h, \ldots)$ & $-0.01(0.80)$ & $-0.53(0.78)$ & 0.52 & $5.01(1.53)$ & $4.12(1.62)$ & 0.89 \\
\hline overall mean & $\varnothing 0.16$ & $\varnothing-0.45$ & $\varnothing 0.61$ & Ø 5.29 & $\varnothing 4.26$ & $\varnothing 1.03$ \\
\hline
\end{tabular}



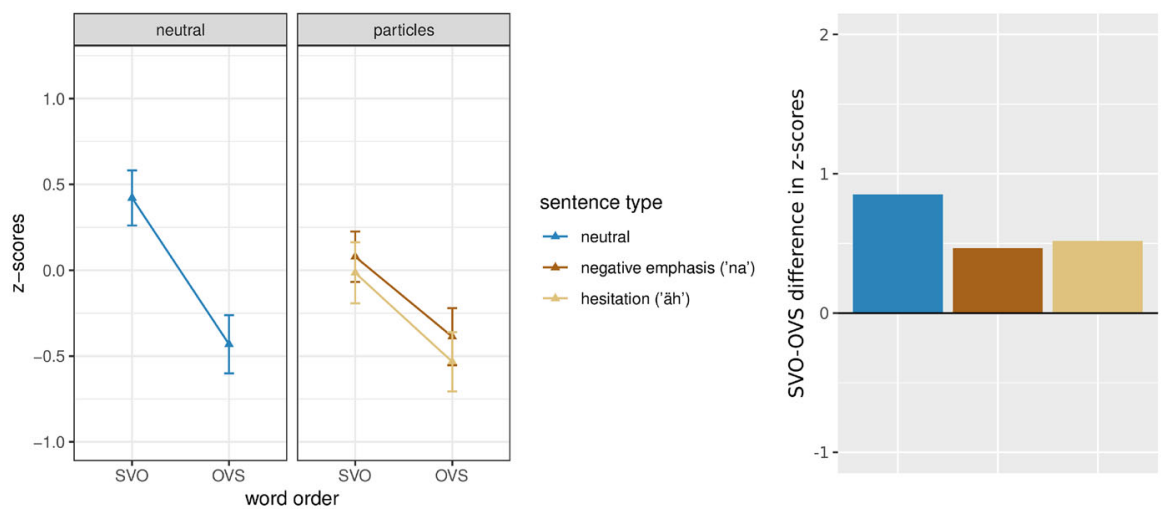

Fig. 6 Mean acceptability in terms of $z$-scores for Experiment 6 (left plot; error bars correspond to 95\% confidence intervals) and mean acceptability difference between SVO and OVS (right plot)

$(t=2.19, p=0.04)$. No significant interaction with word order was found in comparison to sentences with the emphatic particle na $(t=-0.64, p=0.52)$.

\subsubsection{Discussion}

The results show that the hesitation marker $\ddot{a} h$ 'er' reduces the size of the SVOOVS acceptability difference to a similar extent as the particle na signalling low informativity. If our assumption is correct that the former expression merely indicates an informal register/spoken modality, we have to conclude that register/modality is a factor potentially influencing the relative acceptability of OVS structures (in comparison to SVO).

This provides an alternative explanation for the apparent effect of emphasis in Experiment 3, and the explanation might also carry over to the differences between subjects like the idiot and the man observed between Experiments 1 and 2. It also provides an explanation for the partially different results of Experiments 3 and 4. In Experiment 4, we did not replicate the clear difference between neutral and emphatic sentences that we found in Experiment 3; instead, we found that the explicitly non-emphatic context differed from both the neutral and the emphatic one. In view of the results of Experiment 6, we can reconcile these findings: it is thus plausible that the difference found in Experiment 3 was in fact due to the confounding factor register and not due to emphasis.

Could register also have confounded Experiments 4 and 5? As for Experiment 4, all items were preceded by a rather informal sentence, including the emphasisneutral context ('I can tell you that...'). However, there was one subtype of emphasis-excluding sentence that involved a particle, namely ach 'eh' in Ach, das ist nicht der Rede wert 'Eh, it's not worth mentioning', which might be perceived as inducing an even higher degree of informality. We conducted a post hoc analysis to check if this subset of non-emphatic items (about half of them) showed a different pattern due to the presence of the particle. According to a linear mixed model, the 
factor presence of ach did not show a significant main effect, nor did it enter any significant interaction. However, within the non-emphatic materials, visual inspection showed a trend that is compatible with our assumptions about register above. When the introductory text with ach was used, the pattern looks more similar to the neutral and the emphatic context: the acceptability difference between pronoun and given DP is reduced (trend towards a three-way interaction between presence of ach, word order, and subject type). The fact that we found a significant difference between the non-emphatic context and the other two in our analysis of Experiment 4 in spite of this potential confound (which was working against finding a difference) strengthens the point that there is real difference between them.

We did the same post hoc analysis for Experiment 5, which also contained ach in about half of the items. No significant main effect of ach nor any interaction with it was found. Again, visual inspection showed a general trend in the direction of a reduced difference between pronoun and given DP when $a c h$ was present; this was the case for all constructions. For both groups of items (with and without $a c h$ ), it holds that the difference between DP and pronoun was smaller in the relative clause and in the wh-question than in the broad focus condition, even though the differences were overall numerically smaller without $a c h$.

We thus think that our main conclusions drawn from Experiments 4 and 5 are not affected by the findings concerning register (although it would be interesting to follow up on the observed trends with respect to the presence/absence of ach in future research), but some of our conclusions drawn from Experiment 3 are. ${ }^{15}$ It is plausible that Experiment 4 reflects the influence of emphasis more clearly than Experiment 3: whereas sentences containing markers of emphasis do not differ much from neutral ones (as long as an emphatic interpretation is available), sentences in which emphasis is contextually excluded show a different behavior with respect to object fronting.

\subsection{Experiments 7 and 8: register of surrounding materials}

The aim of Experiments 7 and 8 was to test whether object fronting can be facilitated by informal register even if this factor is not manipulated within the target items themselves, but only in the filler materials. If so, this would provide a method to manipulate the register factor without introducing potential confounds (e.g., the presence of particles) into the critical items themselves. It would also suggest that controlling for register in the fillers is crucial when testing constructions which might be sensitive to this manipulation.

\subsubsection{Participants and procedure}

Thirty-two native speakers of German took part in Experiment 7, and 40 took part in Experiment 8. Both experiments were conducted online, using the tools

\footnotetext{
15 For some of the findings of Experiment 3, we think that they cannot be reduced to a register effect: the difference between matrix and embedded clauses concerning the ease of preposing (see also Wagner 2009 ) is certainly not a register phenomenon.
} 
SoSciSurvey and L-Rex (Starschenko 2019), respectively. Two different questionnaires were constructed, which contained the same 16 items, but a different set of 32 fillers with neutral/informal register, which will be described in more detail below. In Experiment 7, each subject saw only one of these questionnaires, i.e., register was a between-subjects factor. In Experiment 8, half of the participants first filled in the questionnaire with neutral fillers and after approximately 2 weeks they filled in the questionnaire with informal fillers. The other half of the participants first received the questionnaire with informal fillers and later the one with formal fillers. We thus obtained ratings for both levels of register from each participant while balancing the order of presentation.

\subsubsection{Design and materials}

The same materials were used for Experiments 7 and 8. For the target items, we used a broad focus context and two answer variants: a subject-initial sentence and an object-initial one, both with a definite, discourse-given DP as the subject, as illustrated below.

$$
\begin{aligned}
& \text { Context: Was macht der Nachbar? } \\
& \text { 'What is the neighbor doing?' } \\
& \text { a. Der Mann grillt Würstchen. } \\
& \text { the man grills sausages } \\
& \text { b. Würstchen grillt der Mann. } \\
& \text { 'The man is grilling sausages.' }
\end{aligned}
$$

The other factor, register, had two levels: informal, familiar register and formal, distant register. The proportion of target items to fillers was 1:2. In addition, six 'anchor' items were included. Their purpose was to ensure that if an effect of the informal fillers on the object-initial sentences was found, this was not due to an unspecific acceptability raising effect, but indeed affected only the object-initial structures. The anchor items were grammatical, but contained a locally ambiguous object relative clause. We expected intermediate acceptability ratings due to processing difficulty.

In a small-scale pretest, 12 participants rated potential filler materials for familiar/informal versus distant/formal register. Based on the pretest, we chose 4 constructions that were rated as the clearest indicators for a familiar/informal register, including left dislocation, topic drop, exclamatives, and the use of tun 'do'. Additionally, colloquial particles, shortened word forms, and the informal second person pronoun $d u$ rather than the formal/distant one Sie were used to strengthen the impression of informal speech between interlocutors with a close relationship. For each of these informal fillers, a formal variant was constructed, which did not include any of the above markers. This is illustrated in 22 and 23. 
(22) Example of an informal filler (with left dislocation):

Wie war's denn gestern im Zoo?

how was.it PART yesterday in.the zoo

'How was it at the zoo yesterday?'

Gestern im Zoo, da haben wir 'nen Eisbären gesehen. yesterday in.the zoo there have we a ice.bear seen

'Yesterday at the zoo, we saw an ice bear.'

(23) Example of a formal filler:

Wie war es gestern im Zoo?
how was it yesterday in.the zoo
'How was it in the zoo yesterday?'
Wir haben gestern im Zoo einen Eisbären gesehen.
we have yesterday in.the zoo a ice.bear seen
'We saw an ice bear at the zoo yesterday.'

\subsubsection{Results}

The results are summarized in Table 7 and illustrated in Fig. $7 .^{16}$

The factors register and word order were sum-coded for the statistical analysis.

According to a linear mixed model with z-scores as the dependent variable, there was no significant interaction between register and word order $(t=1.26, p=0.22)$, only a significant main effect of word order $(t=7.58, p<0.001)$ and register $(t=2.68, p=0.01)$ in Experiment 7 .

According to a linear mixed model with absolute rating as the dependent variable, there was no significant interaction between register and word order $(t=1.66, p=0.11)$ nor a main effect of register $(t=0.51, p=0.62)$, only a significant main effect of word order $(t=7.56, p<0.001)$ in Experiment 7.

For the analysis of Experiment 8, round (i.e., whether the stimulus was part of the first or the second questionnaire that the subject filled in) was additionally included as a fixed factor.

According to a linear mixed model for Experiment 8 with z-scores as the dependent variable, there was no significant interaction between register and word order $(t=0.83, p=0.41)$. All factors showed a significant main effect in that SVO was overall rated higher than OVS, informal register was rated higher than formal register, and higher ratings were given in round 2 than in round 1 (all $t \mathrm{~s}>3$, all $p s<0.001)$. A significant interaction between word order and round $(t=2.29$,

\footnotetext{
16 Absolute ratings rather than $z$-scores are exceptionally displayed in the plot for Experiment 7, and we report the statistical analysis for both types of dependent variable. The reasoning behind it is that whereas calculating $z$-scores is a way to normalize participants' ratings in a within-subjects design, in a betweensubjects design this transformation might obfuscate real differences caused by the factor that was manipulated between subjects. To facilitate comparison, we do the same for Experiment 8 .
} 
Table 7 Mean acceptability (in terms of $z$-scores/original ratings on the 7-point scale) for each condition of Experiments 7 and 8, as well as mean SVO-OVS differences; standard deviation in parentheses

\begin{tabular}{|c|c|c|c|c|c|c|}
\hline & \multicolumn{3}{|c|}{ Mean acceptability ( $z$-scores) } & \multicolumn{3}{|c|}{ Mean acceptability (7-point scale) } \\
\hline & SVO & OVS & diff. & SVO & OVS & diff. \\
\hline \multicolumn{7}{|l|}{ Exp. 7} \\
\hline neutral register & $0.05(0.71)$ & $-0.87(0.69)$ & 0.92 & $5.25(1.53)$ & $3.55(1.58)$ & 1.70 \\
\hline informal register & $0.21(0.78)$ & $-0.48(0.87)$ & 0.69 & $5.13(1.59)$ & $4.02(1.62)$ & 1.11 \\
\hline overall mean & $\varnothing 0.13$ & $\varnothing-0.67$ & $\varnothing 0.80$ & $\varnothing 5.19$ & $\varnothing 3.79$ & Ø 1.41 \\
\hline \multicolumn{7}{|l|}{ Exp. 8-round 1} \\
\hline neutral register & $0.03(0.95)$ & $-1.09(1.05)$ & 1.12 & $5.03(1.68)$ & $3.02(1.71)$ & 2.01 \\
\hline informal register & $0.52(1.27)$ & $-0.65(1.31)$ & 1.16 & $5.29(1.62)$ & $3.50(1.73)$ & 1.79 \\
\hline overall mean & $\varnothing 0.28$ & $\varnothing-0.87$ & $\varnothing 1.14$ & $\varnothing 5.16$ & $\varnothing 3.26$ & $\varnothing 1.90$ \\
\hline \multicolumn{7}{|l|}{ Exp. 8-round 2} \\
\hline neutral register & $0.54(1.56)$ & $-0.33(1.40)$ & 0.88 & $5.42(1.63)$ & $4.11(1.42)$ & 1.31 \\
\hline informal register & $0.76(0.97)$ & $-0.23(1.15)$ & 0.99 & $5.71(1.59)$ & $4.01(1.92)$ & 1.70 \\
\hline overall mean & $\varnothing 0.65$ & $\varnothing-0.28$ & $\varnothing 0.94$ & $\varnothing 5.57$ & $\varnothing 4.06$ & $\varnothing 1.51$ \\
\hline
\end{tabular}
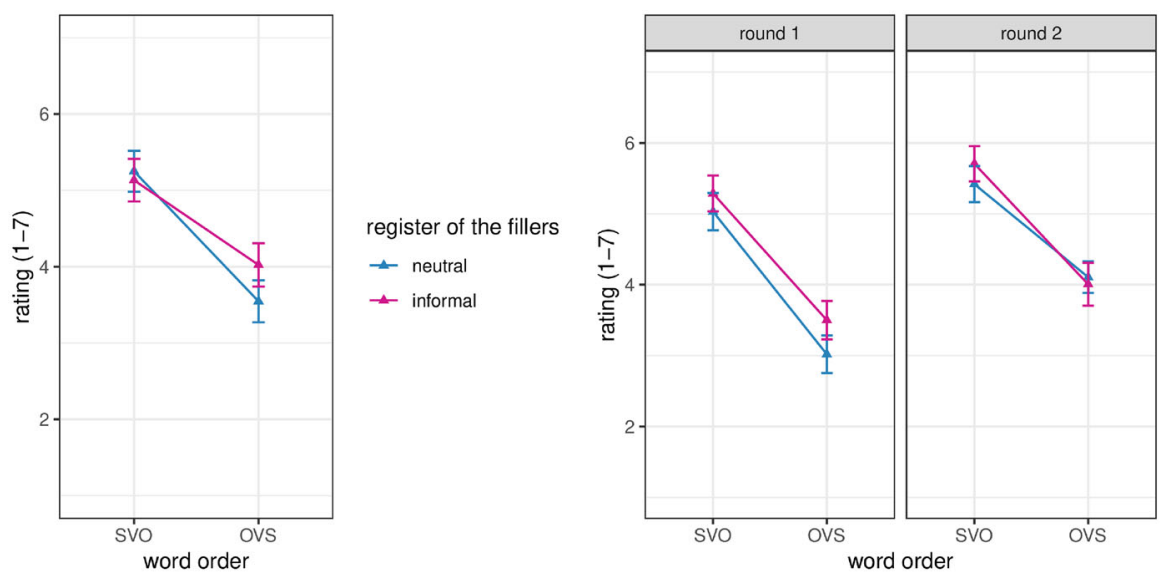

Fig. 7 Mean acceptability in terms of absolute ratings for Experiment 7 (left plot) and Experiment 8 (right plot). Error bars correspond to 95\% confidence intervals

$p<0.02)$ was found: the SVO-OVS difference became smaller in the second round. The three-way interaction between all three factors was not significant $(t=-0.15, p=0.89)$

A linear mixed model for Experiment 8 with absolute rating as the dependent variable also showed a significant main effect of all factors (all $t \mathrm{~s}>3$, all $p$ s $<0.001)$, as well as a significant interaction between word order and round $(t=3.03, p=0.003)$. No significant interaction between word order and register $(t=0.67, p=0.50)$ nor a significant three-way interaction $(t=-0.84, p=0.41)$ were found. 
The mean absolute rating for the anchor items in Experiment 7 was 3.72 in the questionnaire with informal fillers, and 3.84 in the questionnaire with formal fillers. In Experiment 8, they received mean ratings of 3.75 (round 1, neutral fillers)/4.22 (round 1, informal fillers)/4.32 (round 2, neutral fillers)/4.38 (round 2, informal fillers).

\subsubsection{Discussion}

Experiment 7 failed to show a significant interaction between register and word order when register is manipulated not in the test items themselves, but in the surrounding filler materials. However, the variability in subjects' sensitivity to the word order manipulation was relatively high overall, which might have impeded finding a significant interaction in the between-subjects design. In Experiment 8, we therefore replicated Experiment 7 using a within-subjects design to exclude this possibility. The results support the view that there is indeed no reliable effect of the register of filler materials on the critical items: again, no significant interaction between register and word order was found, and the trend towards a reduced SVOOVS difference with informal fillers that was observed in Experiment 7 was not replicated. Instead, we found a general increase in acceptability and a reduction of the SVO-OVS difference when participants rated the same items a second time in round 2. This points towards a training/satiation effect, which could be an interesting subject for future research. This effect seems to be at least partly construction-specific, because the anchor items were not generally raised to the same degree-when surrounded by informal fillers, they received almost constant ratings across the two rounds.

An anonymous reviewer suggested that we check for a potential trial effect (e.g., by comparing the results in the first half of the questionnaire to those in the second half): if the fillers had an effect on the critical items, one might expect that the effect becomes stronger during the course of the experiment because participants become gradually aware of the register of the fillers and react to it. For Experiment 7, the order of presentation was unfortunately not recorded, so we can only report observations about Experiment 8 in this respect. A post hoc look at the anchor items in Experiment 8 is compatible with the reviewer's conjecture that participants might become more tolerant in general while responding to the informal questionnaire (mean anchor item ratings: 4.0 in the first half of the informal questionnaires and 4.6 in the second half; 4.0/4.1 in the formal questionnaires). The filler ratings themselves did not change in this way (informal: 4.4/4.4, formal: 5.8/5.7). The critical items were almost stable in the SVO conditions (5.3/5.4) but showed an increase in the ratings in the OVS conditions (3.4/3.9); contrary to the anchor items and to our expectation about the register effect, however, this increase was stronger in the questionnaires with neutral fillers (3.3/3.9) than with informal fillers (3.6/3.9). 


\section{Conclusion}

In our series of acceptability rating experiments, we investigated how formal properties of crossed elements and interpretative properties of fronted elements influence the acceptability of object-initial sentences in German.

Subjects that are discourse-given, definite DPs or definite pronouns are easier to cross than discourse-new, indefinite DPs in the course of object fronting. This is a robust finding: it was observed in Experiment 1 and replicated in Experiment 2. It is compatible with prosodic approaches as proposed by Féry and Drenhaus (2008), Fanselow and Lenertová (2011), and Wierzba (2017), who all assume that the need to accent a discourse-new DP poses a problem in object-initial structures. Theories of left-peripheral movement that only make a distinction between pronouns and phrases with respect to intervening elements cannot capture this observation. Experiment 5 supports the view that the phenomenon is not reducible to a similar effect that was found in relative clauses in processing studies-we do not observe an advantage of pronoun over DP in the acceptability of object relative clauses. Open issues for future research include the unexplained behavior of repeated DPs and the indefinite pronoun jemand 'someone', and disentangling definiteness from givenness.

In further experiments, we investigated the influence of emphasis. We found that emphasis indeed interacts with the subject type factor (Experiment 4), as predicted by Frey (2010): crossing discourse-given DPs is only as acceptable as crossing a pronoun when an emphatic interpretation is possible. Discourse-new DPs, on the other hand, are always harder to cross. These results are compatible with the assumption that both the prosodic approaches mentioned above and Frey's emphasis-based model describe a correct generalization: crossing discourse-new DPs is always hard due to prosodic problems. Discourse-given DPs and pronouns do not pose a prosodic problem, but moving across a discourse-given DP subject (i.e., skipping a phrase that could potentially be fronted instead of the object) needs to be licensed in some way, e.g., by emphasis. Experiment 5 suggests that emphasis is similar to other licensing operators in this respect: $w h$-movement, for example, does not show an advantage of pronominal subjects over DPs, either.

A partially deviating pattern was found in Experiment 3, where we compared 'neutral' sentences without any emphatic element to sentences with emphatic particles and found a difference in the relative acceptability of object fronting across a DP. In Experiment 4, on the other hand, these conditions behaved similarly, and the effect of emphasis manifested itself only in interaction with subject type. This divergence between the experiments might have to do with a register effect. Support for this conjecture comes from Experiment 6, in which we compared informal emphatic particles with informal non-emphatic ones. The finding that the presence of emphatic expressions can correlate with an informal register suggests that this is an important potential confound that needs to be carefully controlled when these factors are investigated empirically. In Experiment 7, we tested whether the register of surrounding filler materials can also affect the acceptability of object fronting, but failed to find a significant result. 
One limitation of our studies is that we chose to interpret only the relative acceptability of object fronting (in comparison to corresponding subject-initial sentences) to factor out effects that are not directly caused by the word order manipulation. It would be desirable to understand the absolute rating patterns better; but for this, more research would be required to identify factors that cause the differences that we observe in the baseline SVO sentences. It can also be noted that none of the factors that we investigated here fully reduces the acceptability difference between SVO and OVS to zero, meaning that they are not factors that strongly license OVS in the sense of Weskott et al. 2011 (who identified a factor that can even lead to a preference for OVS over SVO, namely the part-whole relation). All effects on the relative acceptability of OVS sentences were relatively subtle with respect to their effect size. However, some of them were retested in several of our experiments, and turned out to be robustly replicable (e.g., that crossing indefinite, discourse-new DPs leads to a particularly large acceptability decrease in comparison to other subject types, as found in Experiments 1, 2, and 4). For the effects that we were only able to test once so far (e.g., the interaction between emphasis and subject type), replication would be desirable in future research.

In conclusion, we hope to have contributed a useful basis of empirical evidence to a field of research in which intuitions tend to be subtle and gradient, and to have pointed out some directions in which further research of this kind would be promising.

Acknowledgements Open Access funding provided by Projekt DEAL. We are grateful to editor Susi Wurmbrand and three anonymous reviewers for their comments and questions, which helped us to improve this paper significantly. We would also like to thank Radek Šimík for discussion of the experiments, Jana Häussler for sharing scripts for experimental set-up and analysis, Reinhold Kliegl for statistical advice, and our student assistants Verena Ehrenberg, Anna-Janina Goecke, Ulrike May, Maxine Prothmann, Sophie Rentschler, and Johannes Rothert for their support in constructing the materials, conducting the experiments, and typesetting the manuscript.The research reported here was supported by the Deutsche Forschungsgemeinschaft (DFG), Grant SFB 632, project A1 (Fanselow/Vicente). Supplementary files to this article (experimental materials and results) are available at the Open Science Framework under https://osf.io/jhdxy/.

Open Access This article is licensed under a Creative Commons Attribution 4.0 International License, which permits use, sharing, adaptation, distribution and reproduction in any medium or format, as long as you give appropriate credit to the original author(s) and the source, provide a link to the Creative Commons licence, and indicate if changes were made. The images or other third party material in this article are included in the article's Creative Commons licence, unless indicated otherwise in a credit line to the material. If material is not included in the article's Creative Commons licence and your intended use is not permitted by statutory regulation or exceeds the permitted use, you will need to obtain permission directly from the copyright holder. To view a copy of this licence, visit http:// creativecommons.org/licenses/by/4.0/.

\section{Appendix}

\section{Experiment 9: repeated name experiment}

The aim of this experiment was to test the hypothesis that the unexpectedly large SVO-OVS difference for sentences containing a repeated DP was due to a repeated 
name penalty interacting with object position. The repeated name penalty is mainly known from language processing research. It refers to the phenomenon that it takes longer to process a DP that is identical in form to a coreferential DP in the immediately preceding utterance than a pronoun, especially in subject position (Gordon et al. 1993). The repeated name penalty has been shown to influence grammaticality judgments as well (Gordon and Hendrick 1997). The idea of this experiment is to compare the type of item that was used in our Experiments 1 and 2 to a type of item in which the use of a repeated DP is warranted, because a pronoun would be ambiguous.

\section{Participants and procedure}

Twenty-seven native speakers of German participated in this online questionnaire study. The procedure was the same as described for the Experiment 1 . The 18 items for the current study were intermixed with 48 fillers/materials from other studies (including Experiment 6 from this paper). In sum, each participant rated 66 stimuli.

\section{Design and materials}

The materials were constructed in a $2 \times 3$ design, with the factors word order and object type. Two of the levels of object type were adopted directly from Experiment 2 , where they were referred to as coreferential DP and repeated DP. For both these object types, the antecedent was in the immediately preceding clause. The third type of object was also a repeated DP, but in that case there was an intervening utterance between it and its antecedent. This utterance contained a noun with the same number and gender specification. Thus, in this case the alternative of using a pronoun instead of repeating the DP is not as readily available, as there would be another potential antecedent for the pronoun. Without a direct pronominal competitor, the repeated name penalty should be weakened.

(24) a. Warum ist hier so viel Rauch? Was hat der Nachbar gemacht?

'Why is the room filled with smoke? What did the neighbor do?'

$\begin{array}{lll}\text { Der Mann hat } & \text { Würstchen } \\ \text { the man } & \text { has } & \text { gausages } \\ \text { grilled }\end{array}$

'The man has grilled sausages.' (coref. object, close antecedent)

b. Warum ist hier so viel Rauch? Was hat der Nachbar gemacht?

'Why is the room filled with smoke? What did the neighbor do?'

$\begin{array}{llll}\text { Der Nachbar } & \text { hat } & \text { Würstchen } & \text { gegrillt. } \\ \text { the neighbor }\end{array}$

'The neighbor has grilled sausages.' (repeated object, close antecedent)

c. Was hat der Nachbar gemacht? Warum ist hier so viel Rauch?

'What did the neighbor do? Why is the room filled with smoke?'

$\begin{array}{lll}\text { Der Nachbar } & \text { hat Würstchen } & \text { gegrillt. } \\ \text { the neighbor }\end{array}$

'The neighbor has grilled sausages.' (coref. object, distant antecedent) 
Table 8 Mean acceptability (in terms of $z$-scores/original ratings on the 7-point scale) for each condition of Experiment 9, as well as mean SVO-OVS differences; standard deviation in parentheses

\begin{tabular}{|c|c|c|c|c|c|c|c|}
\hline \multirow[t]{2}{*}{ obj. type } & \multirow[t]{2}{*}{ Antecedent } & \multicolumn{3}{|c|}{ Mean acceptability ( $z$-scores) } & \multicolumn{3}{|c|}{ Mean acceptability (7-point scale) } \\
\hline & & SVO & OVS & diff. & SVO & OVS & diff. \\
\hline coref. & close & 0.44 & -0.62 & 1.06 & 5.73 & 3.94 & 1.80 \\
\hline repeated & close & 0.71 & -0.50 & 1.23 & 6.19 & 4.09 & 2.10 \\
\hline repeated & distant & 0.72 & -0.51 & 1.22 & 6.20 & 4.06 & 2.14 \\
\hline overall mean & & $\varnothing 0.62$ & $\varnothing-0.55$ & $\varnothing 1.17$ & $\varnothing 6.04$ & $\varnothing 4.03$ & $\varnothing 2.01$ \\
\hline
\end{tabular}
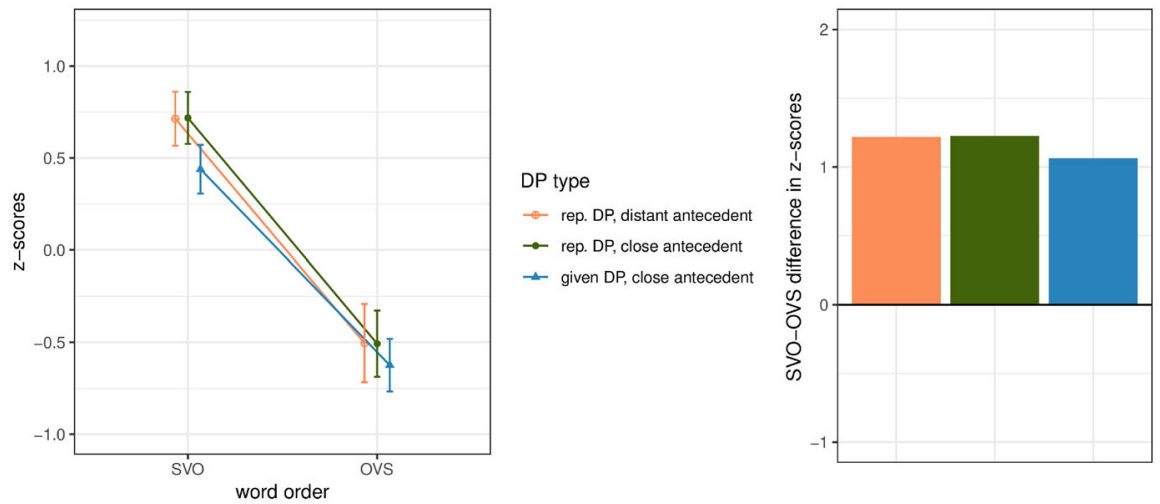

Fig. 8 Mean acceptability in terms of $z$-scores for Experiment 9 (left plot; error bars correspond to $95 \%$ confidence intervals) and mean acceptability difference between SVO and OVS (right plot)

\section{Results}

The results are summarized in Table 8 and illustrated in Fig. 8.

We analyzed the data using a linear mixed model, following the recommendations for identifying parsimonious models. Sum coding was used for the word order factor. For the DP type/antecedent factor, treatment coding with the coreferential/close type as the baseline.

No significant interaction with word order was found for the other two levels of the DP type/antecedent factor, neither for repeated DP with a close antecedent $(t=1.49, p=0.14)$, nor for repeated DP with a distant antecedent $(t=1.15$, $p=0.26)$.

\section{Discussion}

We failed to find evidence for an interaction of the repeated name penalty with word order. What is more, the results do not show a repeated name penalty even in the SVO condition: no difference between a repeated DP with a close and a distant antecedent was found. This could indicate that our design was not suitable to detect a repeated name penalty in the first place, maybe due to the fact that the utterance 
that was inserted between the antecedent and the repeated DP did not provide a salient enough alternative referent to block a pronominal expression as a competitor. Thus, we cannot conclude from this experiment whether the repeated name penalty interacts with word order, as we hypothesized based on Experiments 1 and 2 or not, and further research is needed.

\section{References}

Akmajian, Adrian, and Ray Jackendoff. 1970. Coreferentiality and stress. Linguistic Inquiry 1: 124-126.

Bader, Markus, Emilia Ellsiepen, Vasiliki Koukoulioti, and Yvonne Portele. 2017. Filling the prefield: Findings and challenges. In Two perspectives on V2, ed. Constantin Freitag, Oliver Bott, and Fabian Schlotterbeck, 27-49. Konstanz: University of Konstanz.

Bates, Douglas, Martin Mächler, Ben Bolker, and Steve Walker. 2015a. Fitting linear mixed-effects models using lme4. Journal of Statistical Software. https://doi.org/10.18637/jss.v067.i01.

Bates, Douglas, Reinhold Kliegl, Shravan Vasishth, and Harald Baayen. 2015. Parsimonious mixed models. arXiv:1506.04967 [stat.ME].

Behaghel, Otto. 1932. Deutsche Syntax: Eine geschichtliche Darstellung. Bd. 4: Wortstellung. Periodenbau. Heidelberg: Winter.

Bianchi, Valentina, Giuliano Bocci, and Silvio Cruschina. 2016. Focus fronting, unexpectedness, and evaluative implicatures. Semantics and Pragmatics 9 (3): 1-54.

Bierwisch, Manfred. 1963. Grammatik des deutschen Verbs (Studia grammatica 2). Berlin: AkademieVerlag.

Büring, Daniel. 1997. The meaning of topic and focus. The 59th Street bridge accent. London: Routledge.

Bresnan, Joan. 1971. Sentence stress and syntactic transformations. Language 47: 257-281.

Chafe, Wallace. 1976. Givenness, contrastiveness, definiteness, subjects, topics, and point of view. In Subject and topic, ed. Charles N. Li, 25-55. New York: Academic Press.

Cruschina, Silvio. 2012. Discourse-related features and functional projections. Oxford: Oxford University Press.

den Besten, H. 1983. On the interaction of root transformations and lexical deletive rules. In On the formal syntax of the Westgermania, ed. W. Abraham. Amsterdam: John Benjamins.

Drach, Erich. 1939. Grundgedanken der deutschen Satzlehre, 2nd ed. Frankfurt am Main: M. Diesterweg.

Fanselow, Gisbert. 2002. Quirky subjects and other specifiers. In More than words: A festschrift for Dieter Wunderlich, ed. Ingrid Kaufmann and Barbara Stiebels, 227-250. Berlin: Akademie-Verlag.

Fanselow, Gisbert. 2003. Münchhausen-style head movement and the analysis of verb second. In Syntax at sunset 3: Head movement and syntactic theory, (UCLA \& Potsdam Working Papers in Linguistics) ed. Anoop Mahajan. 40-76.

Fanselow, Gisbert. 2004. Cyclic phonology-syntax interaction: Movement to first position in German. In Working papers of the SFB 632: Interdisciplinary studies on information structure 1, eds. Shinichiro Ishihara, Michaela Schmitz, and Anne Schwarz, 1-42. Potsdam: Universitätsverlag Potsdam.

Fanselow, Gisbert. 2016. Syntactic and prosodic reflexes of information structure in Germanic. In The Oxford handbook of information structure, ed. Caroline Féry and Shinichiro Ishihara, 621-641. Oxford: Oxford University Press.

Fanselow, Gisbert, and Denisa Lenertová. 2011. Left peripheral focus: Mismatches between syntax and information structure. Natural Language and Linguistic Theory 29: 169-209.

Fanselow, Gisbert, Denisa Lenertová, and Thomas Weskott. 2008. Studies on the acceptability of object movement to Spec, CP. In The discourse potential of underspecified structures (Language, context and cognition 8), ed. Anita Steube, 413-438. Berlin: De Gruyter.

Féry, Caroline, and Heiner Drenhaus. 2008. Single prosodic phrase sentences. In Interdisciplinary Studies in Information Structures 10, 1-44. Potsdam.

Fiebach, Christian, Matthias Schlesewsky, and Angela Friederici. 2002. Separating syntactic memory costs and syntactic integration costs during parsing: The processing of German WH-questions. Journal of Memory and Language 47: 250-272.

Fox, Danny, and David Pesetsky. 2005. Cyclic linearization of syntactic structure. Theoretical Linguistics 31: $1-45$. 
Frey, Werner. 2004. The grammar-pragmatics interface and the German prefield. Sprache und Pragmatik 52: $1-39$.

Frey, Werner. 2005. Zur Syntax der linken Peripherie im Deutschen. In Deutsche Syntax: Empirie und Theorie, ed. Franz-Josef d'Avis, 147-171. Göteborg: Acta Universitatis Gothoburgensis.

Frey, Werner. 2006. Contrast and movement to the German prefield. In The architecture of focus, ed. Valéria Molnár and Susanne Winkler, 235-264. Berlin: Mouton de Gruyter.

Frey, Werner. 2010. A-bar-movement and conventional implicatures: About the grammatical encoding of emphasis in German. Lingua 120: 1416-1435.

Friedmann, Naama, Adriana Belletti, and Luigi Rizzi. 2009. Relativized relatives: Types of intervention in the acquisition of A-bar dependencies. Lingua 119 (1): 67-88.

Gordon, Peter, Barbara J. Grosz, and Laura A. Gilliom. 1993. Pronouns, names, and the centering of attention in discourse. Cognitive Science 17: 311-347.

Gordon, Peter C., and Randall Hendrick. 1997. Intuitive knowledge of linguistic co-reference. Cognition 62: $325-370$.

Hofmeister, Philip, Laura Staum Casasanto, and Ivan A. Sag. 2014. Processing effects in linguistic judgment data: (Super-)additivity and reading span scores. Language and Cognition 6: 111-145.

Höhle, Tilman. 1982. Explikationen für, normale Betonung ' und ,normale Wortstellung'. In Satzglieder im Deutschen, ed. W. Abraham, 75-152. Tübingen: Narr.

Jacobs, Joachim. 1991. Focus ambiguities. Journal of Semantics 8: 1-36.

Korth, Manuela. 2014. Von der Syntax zur Prosodie. Über das strukturelle Verhältnis zweier Komponenten der Grammatik im Deutschen. Tübingen: Stauffenburg Verlag.

Krifka, Manfred. 1998. Scope inversion under the rise-fall pattern in German. Linguistic Inquiry 29 (1): 75-112.

Krifka, Manfred. 2007. Basic notions of information structure. In Interdisciplinary studies on information structure 6, ed. Caroline Féry and Manfred Krifka, 13-56. Potsdam: Universitätsverlag.

Kuznetsova, Alexandra, Per B. Brockhoff, and Rune H.B. Christensen. 2017. lmerTest package: Tests in linear mixed effects models. Journal of Statistical Software 82 (13): 1-26. https://doi.org/10.18637/ jss.v082.i13.

Leiner, D. J. 2014. SoSci Survey (Version 2.5.00-i) [Computer software]. http://www.soscisurvey.com.

Lenerz, Jürgen. 1977. Zur Abfolge nominaler Satzglieder im Deutschen. Tübingen: Narr.

Müller, Gereon. 2004. Verb-second as vP-first. The Journal of Comparative Germanic Linguistics 7: 179-234.

R Core Team. 2016. R: A language and environment for statistical computing. Vienna: R Foundation for Statistical Computing. https://www.R-project.org.

Reinhart, Tanya. 1981. Pragmatics and linguistics: An analysis of sentence topics. Philosophica 27(1): 53-94. http://logica.ugent.be/philosophica/fulltexts/27-4.pdf.

Schwarzschild, Roger. 1999. Givenness, AvoidF and other constraints on the placement of accent. Natural Language Semantics 7: 141-177.

Selkirk, Elisabeth. 1995. Sentence prosody: Intonation, stress and phrasing. In The handbook of phonological theory, ed. John A. Goldsmith, 550-569. Cambridge: Blackwell.

Selkirk, Elisabeth. 1996. The prosodic structure of function words. In Signal to syntax: Prosodic bootstrapping from speech to grammar in early acquisition, ed. James L. Morgan and Katherine Demuth, 187-214. Mahwah, NJ: Lawrence Erlbaum Associates.

Selkirk, Elisabeth. 2011. The syntax-phonology interface. In The handbook of phonological theory, 2nd ed, ed. J. Goldsmith, J. Riggle, and A. Yu. Oxford: Blackwell.

Speyer, A. 2008. German vorfeld-filling as constraint interaction. In Constraints in discourse, ed. A. Benz and P. Kühnlein, 267-290. Amsterdam: Benjamins.

Sprouse, Jon, Matt Wagers, and Colin Phillips. 2012. A test of the relation between working memory capacity and syntactic island effects. Language 88 (1): 82-123.

Starschenko, A. 2019. L-Rex [Computer software]. https://github.com/2e2a/l-rex.

Thiersch, Craig. 1978. Topics in German syntax. Doctoral Dissertation. Cambridge, MA: MIT.

Titov, Elena. 2012. Information structure of argument order alternations. Doctoral Dissertation, UCL.

Travis, Lisa. 1984. Parameters and effects of word order variation. Doctoral Dissertation. Cambridge, MA: MIT.

Trotzke, Andreas. 2017. Mirative fronting in German. Experimental evidence. Review of Cognitive Linguistics 15 (2): 460-488.

Truckenbrodt, Hubert. 1995. Phonological phrases: their relation to syntax, focus, and prominence. Doctoral Dissertation. Cambridge, MA: MIT. 
Truckenbrodt, Hubert. To appear. Notes on stress reconstruction and syntactic reconstruction. In Reconstruction effects in relative clauses, ed. Manfred Krifka and Mathias Schenner. Berlin: Akademie-Verlag.

Wagner, Michael. 2009. Focus, topic, and word order: A compositional view. In Alternatives to cartography, ed. Jeroen van Craenenbroeck, 53-86. Berlin: Mouton de Gruyter.

Weskott, Thomas, Robin Hörnig, Gisbert Fanselow, and Reinhold Kliegl. 2011. Contextual licensing of marked OVS word order in German. Linguistische Berichte 225: 3-18.

Wierzba, Marta. 2017. Revisiting prosodic reconstruction: An interface-based approach to partial focus and topic fronting in German. Doctoral thesis, Universität Potsdam.

Publisher's Note Springer Nature remains neutral with regard to jurisdictional claims in published maps and institutional affiliations. 